\title{
Does Economic Diplomacy Work? A Meta-analysis of Its Impact on Trade and Investment
}

\author{
Selwyn J. V. Moons and Peter A. G. van Bergeijk \\ International Institute of Social Studies, Erasmus University, The Hague, The Netherlands
}

\section{ECONOMIC DIPLOMACY: AN INTRODUCTION}

刍 ARRIERS to international trade and foreign direct investment (FDI) remain large despite the advances made in communication and transportation technology, massively lower transportation cost and reductions in formal trade barriers. In particular, informal trade barriers, cultural and institutional differences and modi operandi continue to act as intangible barriers that create frictions similar to the well-researched traditional resistance factors (Head and Ries, 2006; Disdier and Head, 2008). Economic diplomacy, the topic of our investigation, is increasingly being recognised as an instrument that can be used to deal with these intangible barriers to trade (e.g. van Bergeijk, 2009; Yakop and van Bergeijk, 2011). Economic diplomacy aims to influence decisions on cross-border economic activities pursued by governments and non-state actors (Bayne and Woolcock, 2003; Okano Heijmans, 2011). Economic diplomacy involves the activities of the government and its (inter)national networks and can be defined as the use of government relations and government influence to enable international trade and investment. Typically, nations interact with other nations through a broad range of actions of (semi)permanent international representations (embassies, consulates and other public sector business support facilities) and diplomatic bilateral activities (trade and state visits). Governments also interact with foreign and domestic companies to stimulate trade and investment through domestic institutions (investment and export promotion offices) that stand under the auspices of economic diplomats (Saner and Yiu, 2003). These domestic institutions support companies in their trade and investment decisions and use information from the diplomatic network, and in many countries, these institutions form the home basis for the trade and investment activities employed within the embassy network. ${ }^{1}$ Economic diplomacy typically is an interdisciplinary subject to the fields of international economics, international political economy and international relations and is receiving increasing attention in all three disciplines (van Bergeijk et al., 2011b).

Economists traditionally have been sceptical about economic diplomacy. Key requirements for government intervention are that the intervention targets markets failure and that the benefits outweigh the costs of intervention. This was contested for economic diplomacy, especially where it concerned export subsidies and export promotion agencies. Seringhaus and Botschen (1991), for example, showed that the utility of export promotion is very limited and that

\footnotetext{
${ }^{1}$ Economic diplomacy has several elements: bilateral economic activities between nations, including the organisation of state and trade visits, use of investment and export promotion agencies and the export promotion activities of the diplomatic network. Note that some of these elements have been labelled 'bilateral economic diplomacy' or 'commercial policy' (Saner and Yiu, 2003; Lee and Hudson, 2004; van Bergeijk, 2009).
} 
export promotion efforts all too often do not address the needs of exporters. Likewise, Gencturk and Kotabe (2001) found that export subsidies make businesses more profitable, but have no effect on their turn-over. In the same spirit, export promotion agencies (EPAs) have received considerable criticism in the 1990s. World Bank publications by Hogan (1991) and Keesing and Singer (1991) criticised the establishment of EPAs especially in countries with high trade barriers where export promotion would serve as a palliative; the effective first best solution is to lower trade barriers. As a result of these influential World Bank studies, many development institutions withdrew their support to EPAs (Lederman et al., 2006).

The economic justification for economic diplomacy is based on (i) the existence of asymmetric information for operating internationally companies and (ii) externalities associated with the collection and sharing of information about market conditions and business opportunities in international markets (Hausmann and Rodrik, 2003). If information is imperfect, markets do not produce Pareto efficient outcomes (Greenwald and Stiglitz, 1986). In the internationalisation decision of firms, imperfect and asymmetric information is often a factor, because it is costly for firms to identify potential business partners and to assess their capabilities (Rauch, 1996; Rangan and Lawrence, 1999). It is likely that this type of information about export markets is under-produced from a societal point of view because first movers cannot reap the full benefits of this information due to free riding rivals (Hausmann and Rodrik, 2003). Local and competing firms will try to restrict the availability of information in order to prevent competitors from entering the market. This is especially problematic when one wants to enter a developing country because published statistics and other sources are scarcer for those markets. Governments may step in by providing 'unique, reliable and impartial access to information such as through the global embassy network and other government channels and contact, which become available through the government's very long term and non-commercial attachment to overseas markets' (Harris and Li, 2005 , p. 74). By supplying information to companies, economic diplomats reduce transaction cost, facilitate international flows (trade and investment) and contribute to a more efficient allocation of capital.

Policymakers consider economic diplomacy relevant for four reasons. First, the share of the former centrally planned economies in world trade has increased (Kowalski et al., 2013). In these countries, government is still regarded as a natural partner in the economy. Second, state enterprises may be the counterpart of a company operating in the international markets. This necessitates entrepreneurs to seek cooperation with their national government in order to equalise the power balance and to level the playing field. Third, (political) uncertainty about international transactions must often be removed or reduced. Government involvement may signal that a transaction will not raise political resistance. Finally, some high-quality information needed for international transactions sometimes requires involvement of government officials. In the slipstream of increased policy relevance, empirical studies on economic diplomacy appeared in leading journals, including Rose (2007), Nitsch (2007), Lederman et al. (2010) and Volpe Martincus et al. (2010a). The academic attention and the popularity of economic diplomacy among policymakers increase the importance of knowledge about the (size) effect and significance of economic diplomacy.

Since the empirical work in the field of economic diplomacy is still evolving, lacking consensus is an issue. We take stock of this literature by providing a meta-analysis of 32 empirical studies published in the period 1986-2011. These studies basically provide us with two 
samples. Sample 1 contains $627 t$-values and sample 2 consists of 963 reported significance levels (both regarding the impact of economic diplomacy on international economic flows; see Figure 1). Importantly, in the larger sample the number of insignificant and negative coefficients exceeds the number of significantly positive coefficients (for sample 1, the share of negative and insignificant $t$-values is 34 per cent). We scrutinise the mixed evidence that is provided by these studies, controlling for differences in methodology, time frame and data characteristics of the 32 studies by doing a meta-regression analysis. This is a research method that enables researchers to synthesise and summarise previously obtained empirical findings for a similar research question in a quantitative and statistically rigorous fashion. Meta-analysis basically is a statistical approach in which the reported results are controlled for the characteristics of the identified primary studies. It therefore both includes and goes beyond a traditional systematic review. The use of a meta-analysis adds value to a traditional review of the literature: a meta-analysis is less prone to subjective bias and more transparent than a traditional literature review because it systematically analyses sources of (quantitative) variation of earlier primary studies (Lazzaroni and van Bergeijk, 2015).

A meta-analysis enables us to combine the results from the different (sub)disciplines where economic diplomacy is gaining ground. This is particularly relevant if only because the topic of economic diplomacy should be studied from a multidisciplinary point of view while empirical studies so far have by and large been mono-disciplinary in focus.

The contribution of this paper is, first, that this is the first meta-analysis of the effects of instruments of economic diplomacy on international economic flows. Like other meta-analyses from the field of economics, we find that research design is an important determinant for significance of the particular instrument(s) under econometric investigation (compare, Ljungwall and Tingvall, 2008; Meyer and Sinani, 2009; Havranek and Irsova, 2010; Mebratie and Van Bergeijk, 2011; Lazzaroni and van Bergeijk, 2015). Second, we identify important methodological issues that can be taken into account in future research not only in the field of economic diplomacy, but also in any emerging field. Third, we develop a logit model of significance levels that allows us to consider 50 per cent more observations. This innovation is relevant to research fields where establishing the meta-sign and its meta-significance already is a relevant finding and where reporting in the primary studies frequently

FIGURE 1

Sample 1 (Based on Reported and Calculated $t$-Values) Versus Sample 2 (Based on Reported Significance Levels)

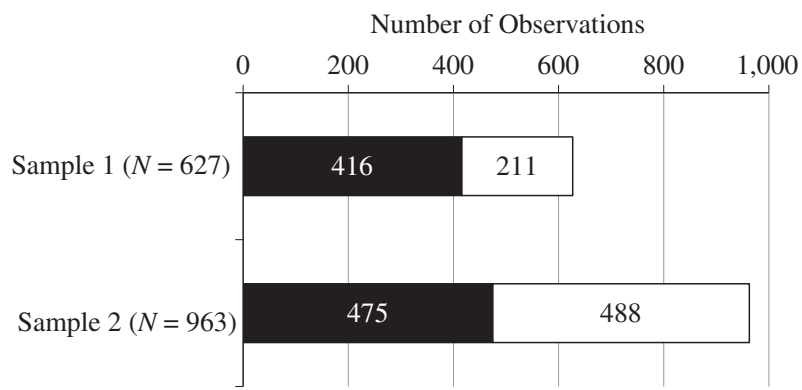

Significantly Positive $\mathrm{p}=0.05 \square$ Insignificant 
is incomplete or inexact. ${ }^{2}$ The fourth contribution is that we show the importance of conducting sensitivity analysis in meta-analysis for cross-disciplinary subjects like economic diplomacy.

The remainder of this paper is structured as follows. Section 2 reviews empirical research that addresses the relation between economic diplomacy and trade and investment flows. We discuss the problems encountered in these studies. Section 3 discusses the construction of our sample and provides descriptive statistics. Section 4 sets out the design of the meta-analysis, and Section 5 presents and discusses the empirical results and conducts a meta-regression sensitivity analysis. Section 6 concludes.

\section{REVIEW OF LITERATURE}

Most studies in our sample use the gravity model that has a long-standing history in analysing the international pattern of bilateral trade and investment flows (van Bergeijk and Brakman, 2010). The primary studies in our sample use economic diplomacy as one of the determinants of international trade and investment. The parameter estimate of economic diplomacy can be interpreted as the partial derivative of international trade (investment) with respect to the particular diplomatic instrument(s) investigated in the primary study.

Until the mid-1990s, the methodology still was rather crude from today's perspective due to limited computing power and data availability. The studies predominantly pertained to cross-sectional analysis of bilateral political indicators based on events data to explain the development of bilateral trade (Pollins, 1989a, 1989b; van Bergeijk, 1992, 1994; Polachek, 1997) and FDI (Nigh, 1985). The empirical works uncovered a positive correlation between, on the one hand, trade (FDI) and, on the other hand, (net) diplomatic cooperation. Differences in the significance, strength and sometimes the sign of the correlations occurred for singleyear studies (van Bergeijk, 1992, 1994) versus pooled cross sections (Nigh, 1985; Pollins, 1989a, 1989b) and for developing versus developed countries (Nigh, 1985). Also the extent to which countries were integrated in the world economy (Pollins, 1989a) and the socio-political system (centrally planned versus market economies; van Bergeijk, 1992, 1994) appeared to be relevant.

The collapse of the USSR for some time reduced research interest in the topic, but in the mid-2000s economic diplomacy returned on the research agenda. Improving on the earlier literature, researchers deployed panel data, advanced econometric methods and more specific tools of economic diplomacy as explanatory variables. The focal point became the international network of countries (consisting of embassies, consulates, the national, local and regional export and investment promotion offices) and the use of that network (trade missions at various levels of diplomatic representation organised within this network).

Researchers at the World Bank published studies on the effectiveness of investment promotion agencies (IPAs) (Morriset, 2003; Harding and Javorcik, 2007) and EPAs (Lederman et al., 2006, 2010). According to these studies, IPAs and EPAs have a strong and statistically significant effect. The studies claimed that on average a 10 per cent increase in the budget of investment promotion leads to a 7.5 per cent increase in FDI flows (Morriset, 2003), that each additional dollar of export promotion increases exports by 40 dollars for the median agency

\footnotetext{
2 One-third of the regression coefficients in our sample are reported without $t$-values or standard errors, but only with insignificance and significance at the 5 and 1 per cent level, respectively.
} 
(Lederman et al., 2006) and that a 10 per cent increase in the budget of export promotion agencies increases exports by 0.6 to 1.0 per cent (Lederman et al., 2010). Later studies on the topic of export promotion and investment promotion produced positively significant effects of much smaller size (Bobonis and Shatz, 2007; van Veenstra et al., 2011). The empirical work that followed the World Bank publications had a somewhat different and wider scope and dealt with the regional effect of export promotion and embassies (Gil et al., 2008; Volpe Martincus et al., 2010a; Gil-Pareja et al., 2011), the effect of the level of development (van Veenstra et al., 2011) and the effect of export promotion on the extensive and intensive margin of trade (Segura-Cayuela and Vilarrubia, 2008; Volpe Martincus et al., 2010a, 2010b; Gil-Pareja et al., 2011; Volpe Martincus and Carballo, 2011). ${ }^{3}$

Others investigated economic diplomacy by focusing on the contribution of the diplomatic service. Rose (2007) was the first to publish on the macroeconomic level effects of the network of embassies and consulates-general (Rose, 2007). The effects of the changes in the international diplomatic network are studied by Afman and Maurel (2010), and the heterogeneity in effects due to different forms of representation in this network are analysed by van Bergeijk et al. (2011a, 2011b). The effects of export promotion units within the embassies are investigated by Gil et al. (2008), Kang (2011), Hajakawa et al. (2010), Creusen and Lejour (2011). Furthermore, research has emerged on the use of the international network via organising trade missions including state visits (Head and Ries, 2006; Nitsch, 2007; Creusen and Lejour, 2011, 2013).

The recent studies report positive and significant coefficients. Rose (2007) finds that the opening of an additional embassy or consulate is associated with 6 to 10 per cent higher exports. Kang (2011) reports that a 10 per cent increase in the budget of export promotion units in embassies increases exports by 2 to 6 per cent. Similarly, according to Hajakawa et al. (2010) this effect is 5 to 6 per cent. Afman and Maurel (2010) calculate that the opening of an embassy has a similar impact as a 2 to 12 percentage points reduction in ad valorem tariff. Controlling for the level of development, van Veenstra et al. (2011), however, find a smaller effect of only 0.5 to 0.9 per cent additional exports when increasing the number of embassies and consulates by 10 per cent. The use of the diplomatic network via trade missions also shows mixed results varying from an export stimulating effect of 6 to 10 per cent for the USA, France and Germany (Nitsch, 2007) to insignificant outcomes for Canada (Head and Ries, 2006). Exploring micro data for the Netherlands, Creusen and Lejour (2011) find a significant export promoting effect of trade missions of 5 to 20 per cent for low-income countries and OECD countries, respectively. Their estimates for missions to high-income countries are insignificant (so that economic diplomacy hardly would seem to be effective in intraOECD trade).

Additionally, the interaction between measures of economic diplomacy is explored and shows that the type of diplomatic representation seems to matter. Embassies have a larger impact on trade than consulates, while honorary consulates on average do not add value (van Bergeijk et al., 2011a, 2011b). Again the effectiveness of both embassies and consulates and EPAs depends on the levels of development of the trade partners. The impact of economic diplomacy seems to be significant in North-South, South-South and South-North trade and

\footnotetext{
3 The number of papers that deal with intensive and extensive margin, while growing, is not yet sufficient to enable a meaningful meta-analysis. See, however, Moons (2012) for a review of the literature.
} 
weak (if at all) for the flows between developed countries (Creusen and Lejour, 2011, 2013; van Veenstra et al., 2011).

The role of economic diplomacy and its relation to FDI flows has received less attention (also in the more recent literature). Next to the earlier mentioned publications of Morriset (2003), Harding and Javorcik (2007), Bobonis and Shatz (2007) on the role of investment promotion, some work has been done on the impact of the bilateral politic/diplomatic relation on FDI flows. The studies show a positive and significant impact of cooperation between countries, similar to the relation found for trade (Keshk et al., 2004; Polachek et al., 2007). Policies that increase economic security, such as similarity in foreign policy, enhance US FDI (Biglaiser and DeRouen, 2007).

It is difficult to draw general conclusions based on the reviewed literature because the findings are rather heterogeneous. This heterogeneity may partially be explained by differences in the characteristics of the primary studies. A general observation is that analyses are often constrained because of limited data availability and that frequently data sets had to be built from scratch by the researchers by collecting primary data through surveys, by inspecting a great many national websites (in many languages) and/or coding of qualitative historical information. As a consequence, the metrics of economic diplomacy vary. Also, some studies only relate to the trade (investment) activities of one source country. Examples are Head and Ries (2006) on the effectiveness of Canadian trade missions, Creusen and Lejour $(2011,2013)$ on Dutch foreign network and its activities, Kang (2011) on the effect of export promotion units for South Korea and Gil et al. (2008), Gil-Pareja et al. (2011) on exports by Spanish regions. The samples of these studies are county specific, and general conclusions cannot be drawn on such a narrow basis. The same is true for analyses for only a limited group of source countries such as Hajakawa et al. (2010) that is limited to only two countries and for many cross sections that only cover one year. Finally, most studies relate to the more developed source countries. Since higher cultural and institutional barriers typically exist at lower levels of development, the sample should ideally cover source and destination countries at different stages of economic development (Yakop and van Bergeijk, 2011). In order to deal with these issues, our meta-analysis combines the information of the individual studies in order to distil the general pattern hidden in the individual studies.

\section{THE DATA}

Our database contains the characteristics of studies that empirically investigate the impact of economic diplomacy on international economic flows. As a starting point, we followed up on the references made in the primary studies that were surveyed by van Bergeijk (2009), checked studies that cited these studies and, importantly, extended the list of studies by searching the EconLit electronic database and the internet, using Google Scholar. ${ }^{4}$ In our search, we used broad keyword listings with the following terminologies: economic diplomacy, diplomacy and (international) trade, diplomacy and FDI, information barriers and diplomacy, embassies, trade missions, consulates, export promotion institutions, export promotion,

\footnotetext{
${ }^{4}$ In constructing a sample for a meta-analysis, it is best practice to use multiple search engines, to check repositories such as RepEc, SSRN and IMF, WTO and World Bank working papers and to follow up on qualitative reviews of literature.
} 
investment promotion agencies and investment promotion institutions. This provided us with a list of published articles, books, working papers and conference papers that investigate the effect of economic diplomacy on trade and FDI.

Not all uncovered studies could be included in our sample. Qualitative papers, mostly from the field of international relations, were not included since we were searching for empirical research. Our initial search delivered effectiveness studies published in the 1990s (Seringhaus and Botschen, 1991; Seringhaus and Rosson, 1998), but these studies do not deal with the impact of economic diplomacy on trade and FDI. Also excluded were studies based on surveys about successful export strategies at the company level (Gencturk and Kotabe, 2001; Bernard and Jensen, 2004; Francis and Collins-Dodd, 2004; Shamsudoha and Ynus Ali, 2006). The search, moreover, provided micro data studies dealing with the effect of economic diplomacy on the margins of trade (Volpe Martincus et al., 2010a, 2010b; van Biesebroeck et al., 2011; Volpe Martincus and Carballo, 2011). These studies, mostly conducted by Inter-American Development Bank researchers, primarily focus on the effects of trade promotion for Latin American countries (Volpe Martincus, 2010; van Biesebroeck et al., 2011 analyse Canada). These papers look into the development of trade patterns of firms that are treated with economic diplomacy, but cannot be included in our sample: they provide information on how overall trade is being influenced by trade promotion detailing the extensive and intensive margin leaving the question of its impact on the level of total trade unanswered. The studies, moreover, report results which are specific to the groups of assisted companies and do not answer the question what the overall (macroeconomic) impact of economic diplomacy is. Our initial search also provided us with a number of studies that used a logit/probit model to estimate the relationship between economic diplomacy and trade/FDI. In these models, the dependent variable is a binary variable; that is, the analysis is concerned with estimating the change in the probability to trade or invest abroad (see, e.g. Alvarez, 2004). As such, the results from these models do not provide information on the size of the change in the level of trade or FDI by the use of economic diplomacy.

We did not use all findings from the studies included in our initial sample. We only included observations that relate to our search for the impact of economic diplomacy on international economic flows. So we use the observations that relate to the effect on all industries and all products and exclude results relating to subsamples of goods and industries. From the following studies, we used the overall or macro findings but not the product, industry or sector-specific results: Reuveny and Kang (1998), Harding and Javorcik (2007), Lederman et al. (2010), Volpe Martincus et al. (2010a), Gil-Pareja et al. (2011) and Hajakawa et al. (2010).

Our final meta-analysis database consists of 32 studies investigating the relationship between economic diplomacy and the macro impact on international flows (Table 1). All primary studies investigate the impact of one or more instruments of economic diplomacy, controlling for a wide range of potentially relevant variables including distance between trading partners, markets size, common borders, common language and preferential trade agreements. In the database, 963 coefficients on the effect of diplomacy and $627 \mathrm{t}$-values are reported. Furthermore, we registered the dependent variable of the primary study, that is, export, import, total trade or FDI, and the different instruments of diplomacy studied in the primary studies. In order to be able to control for methodological differences, we also included other study characteristics such as the number of observations used for the primary regressions, the year of publication, the period under investigation and the econometric method. 


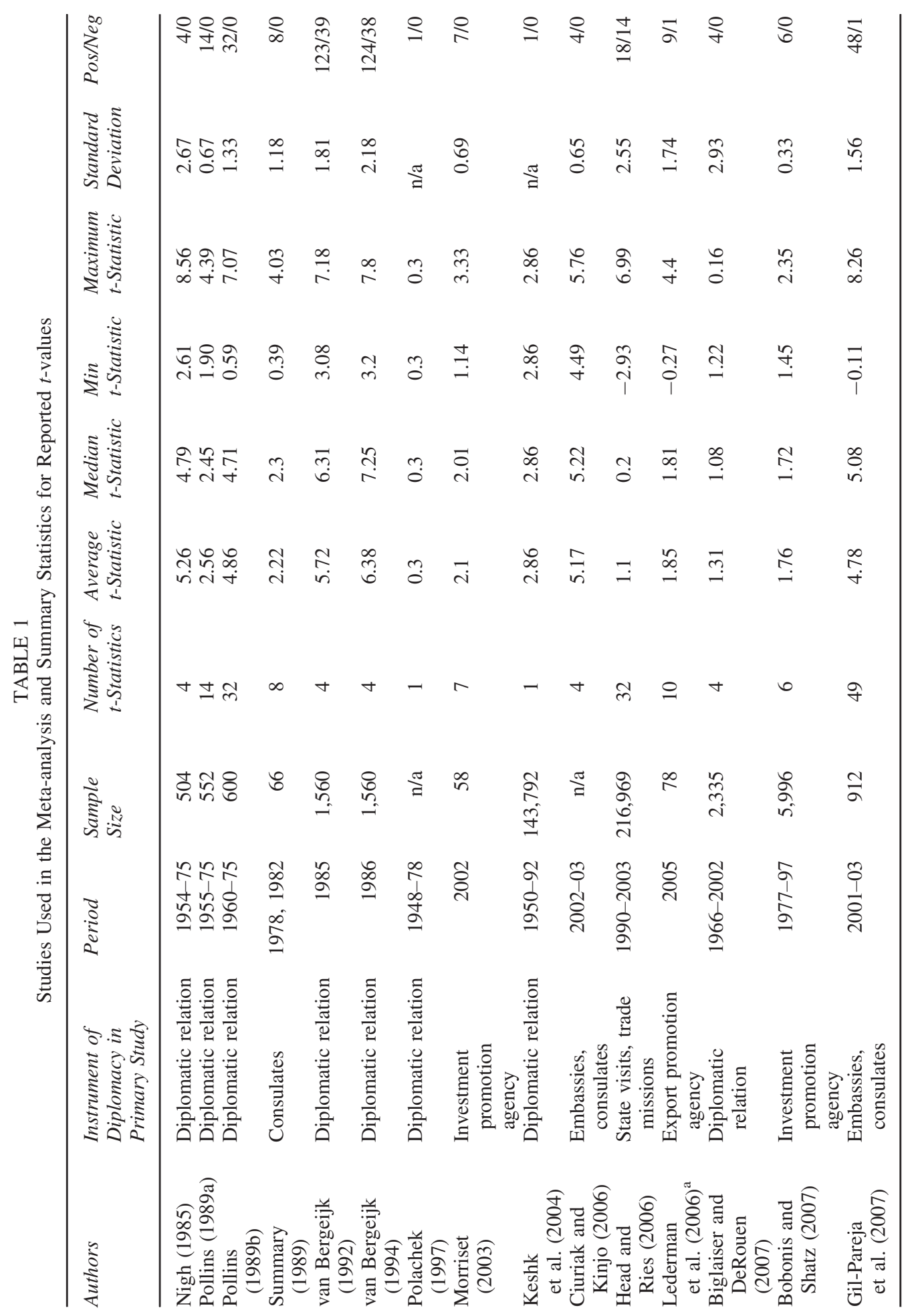




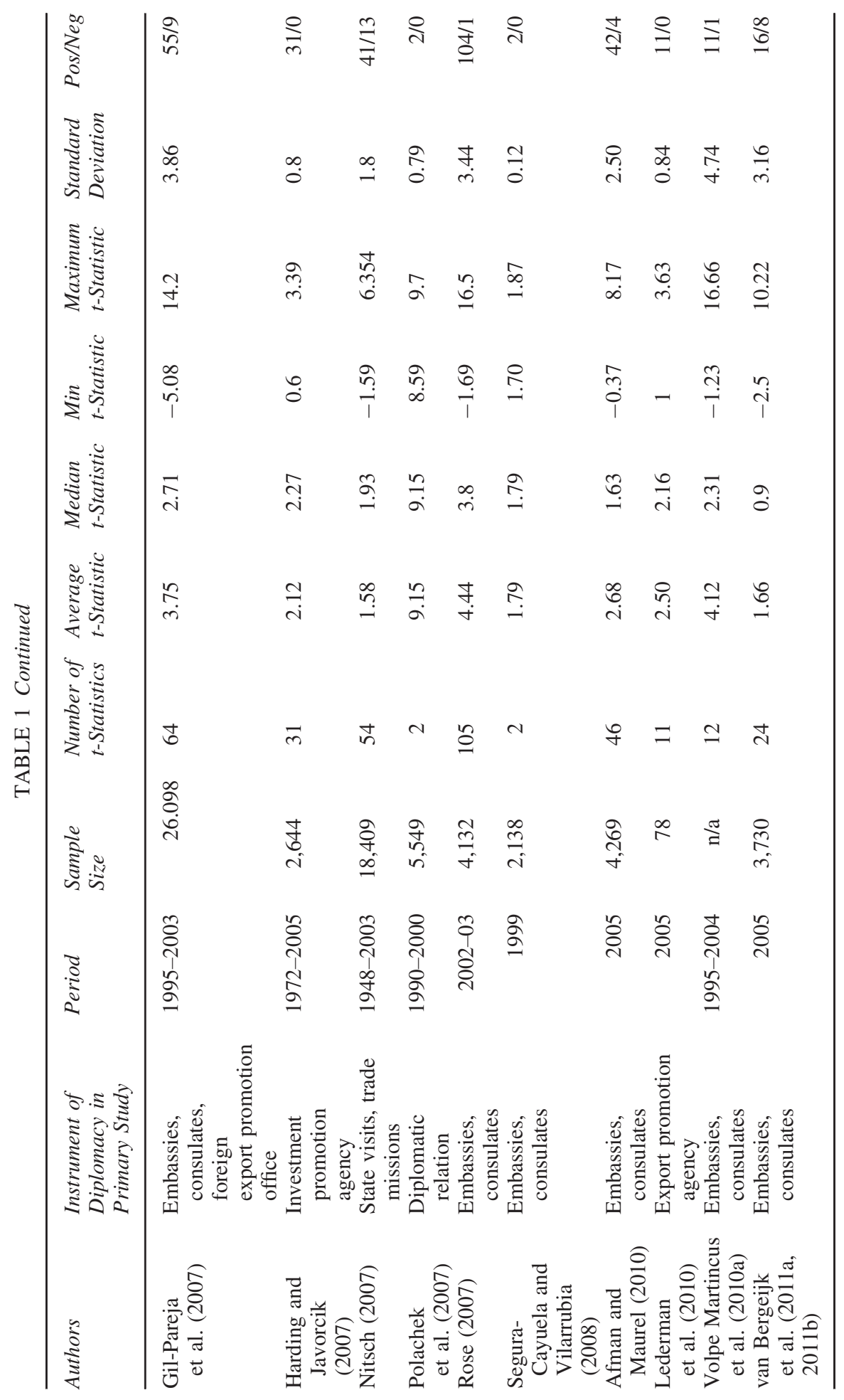




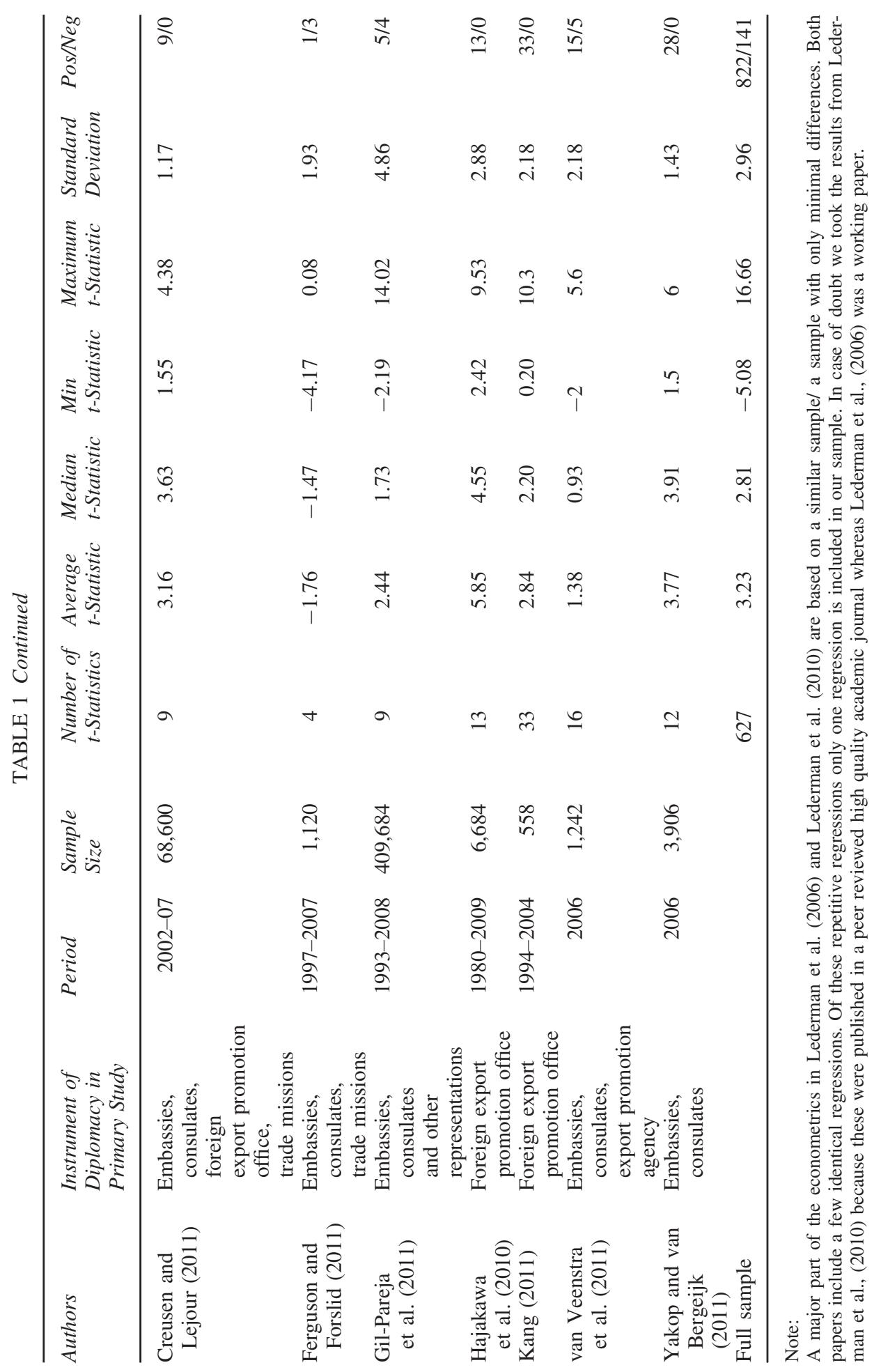


The metrics for economic diplomacy differ widely; that is, economic diplomacy has been reported based on diplomatic event data, ${ }^{5}$ the geography of the foreign network of countries (embassies, consulates and foreign branches of export and investment promotion offices), the activities deployed by the foreign network of countries (trade missions and state visits) and finally activities headquartered in the source economy (export promotion) and destination economy (investment promotion). Also substantial heterogeneity exists with respect to research methods and dependent variables. We created three categories of moderator variables for further analysis: empirical design factors, dependent variable characteristics and instruments of economic diplomacy. Table 2 provides an overview of the various primary study characteristics included in our sample.

While collecting data, we were confronted with substantial heterogeneity in functional forms yielding a mix of linear and non-linear coefficients that, for consistent analysis, should be transformed into elasticities to estimate the size effect of economic diplomacy. In order to calculate the elasticity on average from linear models, we need to know average values of the dependent and explanatory variables, but a number of studies do not report this basic information. We repeatedly, but unsuccessfully, contacted authors of the primary studies to get the missing data. ${ }^{6}$ Moreover, those studies in our sample that fully report basic and essential information do so for the full sample, while regression results are often based on subsamples (e.g. for OECD and non-OECD countries). We do not want to limit the research to regression results that are based on full samples in order to avoid the loss of information regarding the effect of different sample characteristics. As pointed out by Disdier and Head (2008, p. 43): 'different estimates often differ in terms of sample period, method, etc., and therefore withinstudy variation (...) can be used to assess the importance of such variables'. Since we are interested in the impact of research design and subsamples, our missing information problem needs to be solved.

Confronted with these issues, we initially decided to work with the reported or calculated $t$-values, because a $t$-statistic (the estimated coefficient divided by its standard deviation) has no dimension and is often reported or can be calculated from the usually reported statistics. Our method thus solves the difficulties posed by differing units of measurement, specifications and incomplete reporting that makes a traditional meta-analysis of the size effect impossible. By implication, we cannot answer the question of how much economic diplomacy contributes, but we are able to answer whether it contributes significantly and we can also investigate the sensitivity of this conclusion with respect to the methodological characteristics of the primary studies. This more modest goal is appropriate in view of the state of affairs in this field.

In a later stage, it became clear that while 963 coefficients are reported in the 32 primary studies, only $627 t$-statistics could be calculated. Again, we tried to contact the authors of the primary studies with little recourse. To solve this second missing information problem, we enriched our data set by manually counting 'other ways' in which some authors communicated about significance levels. Many authors, for example, use symbols like *,** and *** to report the level of significance of their empirical estimate at the 10,5 or 1 per cent level,

\footnotetext{
${ }^{5}$ Papers investigating the influence of diplomatic relations based on political event data can look into the effect of either more of less interaction between country pairs. These are two sides of the same coin. The analysis of less interaction is of similar size but opposite sign of an analysis on more interaction. For comparability, we changed the sign of the regression coefficients that investigate less interaction.

${ }^{6}$ We thank Lejour and Creusen for providing the necessary information about their 2011 publication.
} 
TABLE 2

Moderator Variables Meta-regression Analysis

\begin{tabular}{|c|c|c|}
\hline $\begin{array}{l}\text { Categories of } \\
\text { Moderator Variables }\end{array}$ & Moderator Var Name & Description \\
\hline \multirow[t]{8}{*}{$\begin{array}{l}\text { Empirical design } \\
\text { factors }\end{array}$} & FIXED EFFECTS & $\begin{array}{l}\text { Dummy, } 1 \text { if fixed effects } \\
\text { estimate; } 0 \text { otherwise }\end{array}$ \\
\hline & NOTOLS & $\begin{array}{l}\text { Dummy, } 1 \text { if other than OLS } \\
\text { estimate; } 0 \text { if OLS }\end{array}$ \\
\hline & COUNTRYSPECIFIC & $\begin{array}{l}\text { Dummy, } 1 \text { if primary sample is } \\
\text { country specific; } 0 \text { otherwise }\end{array}$ \\
\hline & ENDOGENEITY & $\begin{array}{l}\text { Dummy, } 1 \text { if primary analysis } \\
\text { corrects for endogeneity; } 0 \text { otherwise }\end{array}$ \\
\hline & GRAVITY & $\begin{array}{l}\text { Dummy, } 1 \text { if primary regression } \\
\text { is gravity model; } 0 \text { otherwise }\end{array}$ \\
\hline & PANEL & $\begin{array}{l}\text { Dummy, } 1 \text { if panel data; } 0 \text { if } \\
\text { cross-sectional data }\end{array}$ \\
\hline & PRE2000 & $\begin{array}{l}\text { Dummy, } 1 \text { if primary study is } \\
\text { published before } 2000 ; 0 \text { otherwise }\end{array}$ \\
\hline & OBSERVATIONS & $\begin{array}{l}\text { Number of observations in the data } \\
\text { set of primary study }\end{array}$ \\
\hline \multirow[t]{4}{*}{ Dependent variable } & EXPORT & $\begin{array}{l}\text { Dummy, } 1 \text { if exports is dependent } \\
\text { variable primary study; } 0 \text { otherwise }\end{array}$ \\
\hline & IMPORT & $\begin{array}{l}\text { Dummy, } 1 \text { if imports is dependent } \\
\text { variable primary study; } 0 \text { otherwise }\end{array}$ \\
\hline & $F D I$ & $\begin{array}{l}\text { Dummy, } 1 \text { if foreign direct investment } \\
\text { is dependent variable primary } \\
\text { study; } 0 \text { otherwise }\end{array}$ \\
\hline & TOTALTRADE & $\begin{array}{l}\text { Dummy, } 1 \text { if total trade is dependent } \\
\text { variable primary study; } 0 \text { otherwise }\end{array}$ \\
\hline \multirow[t]{8}{*}{$\begin{array}{l}\text { Instrument of } \\
\text { diplomacy }\end{array}$} & EMBASSIES & $\begin{array}{l}\text { Dummy, } 1 \text { if embassies is included } \\
\text { in primary study regressor; } 0 \text { otherwise }\end{array}$ \\
\hline & CONSULATES & $\begin{array}{l}\text { Dummy, } 1 \text { if consulates is included } \\
\text { in primary study regressor; } 0 \text { otherwise }\end{array}$ \\
\hline & EMBASSIESANDCONSULATES & $\begin{array}{l}\text { Dummy, } 1 \text { if embassies and consulates } \\
\text { is included as } 1 \text { group in primary } \\
\text { study regressor; } 0 \text { otherwise }\end{array}$ \\
\hline & FOREIGN EPA & $\begin{array}{l}\text { Dummy, } 1 \text { if foreign export promotion } \\
\text { office is included in primary study } \\
\text { regressor; } 0 \text { otherwise }\end{array}$ \\
\hline & $E P A$ & $\begin{array}{l}\text { Dummy, } 1 \text { if export promotion agency } \\
\text { is included in primary study regressor; } \\
0 \text { otherwise }\end{array}$ \\
\hline & $I P A$ & $\begin{array}{l}\text { Dummy, } 1 \text { if investment promotion } \\
\text { agency is included in primary study } \\
\text { regressor; } 0 \text { otherwise }\end{array}$ \\
\hline & DIPLOMATIC RELATION & $\begin{array}{l}\text { Dummy, } 1 \text { if diplomatic relation is } \\
\text { included in primary study regressor; } \\
0 \text { otherwise }\end{array}$ \\
\hline & STATEVISITS & $\begin{array}{l}\text { Dummy, } 1 \text { if visits by head of state } \\
\text { is included in primary study regressor; } \\
0 \text { otherwise }\end{array}$ \\
\hline
\end{tabular}


TABLE 2 Continued

\begin{tabular}{lll}
\hline $\begin{array}{l}\text { Categories of } \\
\text { Moderator Variables }\end{array}$ & Moderator Var Name & Description \\
\hline TRADE MISSION & $\begin{array}{l}\text { Dummy, 1 if visits by minister of other } \\
\text { representative is included in primary } \\
\text { study regressor; 0 otherwise } \\
\text { Dummy, 1 if state visits dummy is } \\
1 \text { or trade mission dummy is } 1 ; 0 \text { otherwise }\end{array}$ \\
\hline
\end{tabular}

respectively (the levels of significance are also dimensionless). By incorporating these results (where we know the minimal significance level and the sign but not the actual $t$-statistic), we can include an additional 335 regressions in our sample, categorised by their significance level and using binary dummy variables (not significant or significant at the 5 or 1 per cent level, respectively). After this extra effort, only one study that fitted our meta-search criteria dropped out completely. Because of missing $t$-values, or information that would allow us to calculate $t$-values (and also information that would allow us to calculated elasticities) for the effect of economic diplomacy for trade of all industries, we had to drop Reuveny and Kang $(1998)^{7}$ (otherwise the sample could have covered 33 studies).

The reported $t$-statistics (Table 1) vary considerably between studies. A number of studies have insignificant mean and/or median $t$-values (Polachek, 1997; Head and Ries, 2006; Biglaiser and DeRouen, 2007; Bobonis and Shatz, 2007; Nitsch, 2007; Segura-Cayuela and Vilarrubia, 2008; van Bergeijk et al., 2011a, 2011b; Ferguson and Forslid, 2011; van Veenstra et al., 2011). Others such as Gil et al. (2008), Hajakawa et al. (2010) and Volpe Martincus and Carballo (2011), however, report very large $t$-statistics (both positive and negative). These differences could be due to country-specific factors, data characteristics, different time periods, differences in the dependent variable and alternative measures of research design. We explore these sources of heterogeneity in more detail in the next section by means of a multifactor regression in our meta-analysis, but before we do so we provide a first picture of the potential impact of some of the study characteristics. Following other meta-analyses (Sinani and Meyer, 2009; Havranek and Irsova, 2010; Mebratie and van Bergeijk, 2013), we first compute composite bivariate $t$-statistics for a number of variables that we will later use as moderator variables in our meta-regression. The advantage of working with larger (sub)samples of $t$-statistics compared to looking at individual results is that factors with low significance in small samples could be significant in the aggregate even if they are not significant in the primary study, because for a combined sample the large sample's standard deviation is a more precise estimator of the population's standard deviation (Newbold, 1995). The uncertainty caused by the sample estimator as compared to the population's standard deviation is reduced as the sample size increases, and the $t$-distribution more and more fits the standard normal distribution. Tests on the mean of aggregate $t$-statistics are thus more powerful than looking into individual $t$-statistics. We therefore computed the combined $t$-statistics by dividing the sum of $t$-statistics over the square root

\footnotetext{
${ }^{7}$ Reuveny and Kang (1998, Table 6, p. 59) only report the number of significant coefficients, but it is unclear which of these coefficients relate to total trade. Contact with the authors did not solve this problem.
} 
of the number of observations in the full sample. Let $t_{i}$ denote the $t$-statistic corresponding to the specific characteristic of interest. $N$ denotes the number of observations. Then, the combined $t$-statistic $t_{c}$ becomes:

$$
t_{C}=\frac{\sum t_{i}}{\sqrt{N}} \sim N(0,1)
$$

This straightforward calculation of the combined $t$-statistic may, however, be influenced by some studies that contribute particularly large numbers of $t$-statistics, for example because a lot of sensitivity analyses are reported. Examples of such studies in our sample are Gil-Pareja et al. (2007), Nitsch (2007) and Rose (2007). To deal with the overrepresentation of parameters from such studies, we introduce weights per observation. Following Djankov and Murrell (2002) and Wooster and Diebel (2010), normally distributed test statistics are obtained as follows:

$$
\frac{\sum_{k=1}^{m} w_{k} t_{k}}{\sqrt{\sum_{k=1}^{m} w_{k}^{2}}} \sim N(0,1) .
$$

Here $w_{k}$ represents the weight assigned to the $k$-th observation. The weight depends on the total number of observations taken from a particular study; smaller weights are assigned to studies that have larger numbers of reported $t$-values. For example, the study of Gil-Pareja et al. (2007) contributes 64 observations. The weight assigned to each $t$-statistic is $1 /$ $64=0.015625$. If a study contributes only one $t$-statistic, as in our sample Polachek (1997), the weight deployed to this observation is 1 .

Results for aggregated and weighted aggregated $t$-statistics are presented in Table 3 . We did calculations on the full sample of studies and on a subsample excluding outliers to check robustness. For the sample excluding outliers, we dropped the 5 per cent smallest and largest observations, leaving a total number of 565 -statistics. Table 3 shows that the median $t$-statistics for all tested characteristics is always statistically significant except for state visits. This is basically caused by the median $t$-value of Ferguson and Forslid (2011), ${ }^{8}$ but note that Head and Ries (2006) also have report insignificant and negative $t$-values (including in their 'preferred equation'). The state visits $t$-statistic based on the full sample excluding outliers always shows significant aggregate $t$-values. The weighted $t$-statistic is, however, negative.

Across studies, the use of export as a dependent variable is associated with more significant effects of economic diplomacy than studies that use imports, total trade or FDI as the dependent variable. The number of observations related to FDI flows is remarkably lower than the number of observations for exports and imports.

As to the economic diplomacy characteristics, that is the instrument used to explain the effect of economic diplomacy, studies that analyse embassies and consulates on average tend to generate more significant outcomes than state visits, trade missions, EPAs and the more general diplomatic relation measure. The weighted aggregate $t$-statistic suggests that, corrected for the weight of individual studies, studies that only use embassies (as compared to embassies and consulates combined into one dummy) as characteristic for economic diplomacy will be more likely to report significant results.

\footnotetext{
${ }^{8}$ Relatively heavy weights are assigned to the negative $t$-values from the Ferguson and Forslid study with only four observations.
} 


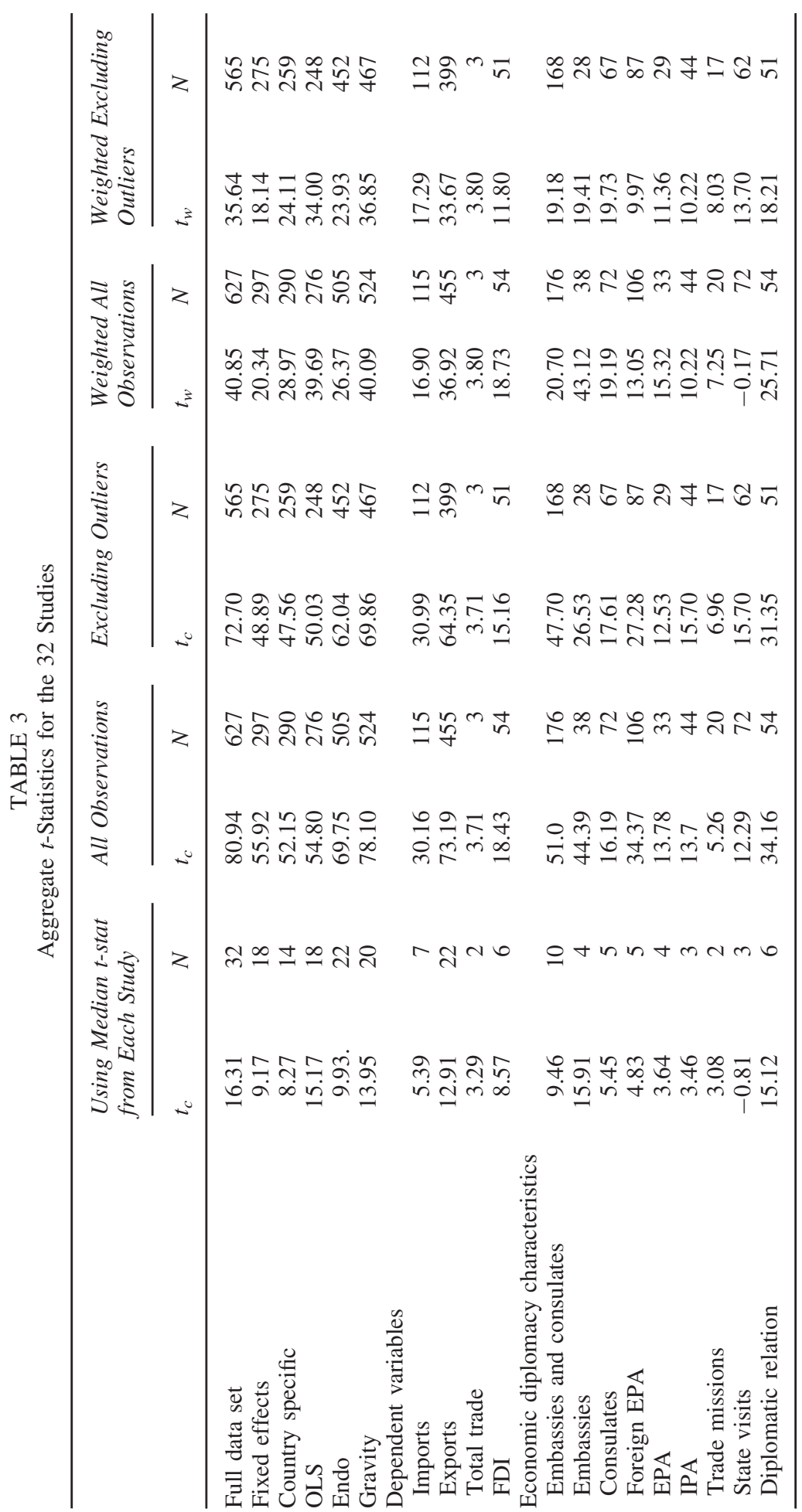


Using a bivariate approach, Table 3 illustrates the extent of heterogeneity, both regarding empirical design, the definition of the dependent variable and the economic diplomacy characteristics. The next step is to investigate this in a multivariate setting. We do so by doing a meta-analysis on our sample of $t$-statistics and significance levels.

\section{DESIGN OF THE META-ANALYSIS}

\section{a. Methodology}

A meta-analysis combines several studies that address a particular research question with a similar design and investigates consistencies and discrepancies of the results of the primary studies. Each primary study is treated equally in meta-analysis, even when it does not use best practice methodology. Actually, alternative weighting schemes are regarded as prone to bias (Stanley, 2001; Rose and Stanley, 2005). Accordingly, all primary studies provide data points in the knowledge-generating mechanism towards the true relationship between economic diplomacy and international economic flows. The analysis investigates the sensitivity of the reported estimates to variations in the assumptions of the primary studies. The essence of meta-analysis is to obtain a single estimate of the effect of interest from statistics reported in each of several primary studies (Bradburn et al., 1998). This methodology is well established in medicine and psychology and increasingly also in economics. The technique provides revised interpretations of earlier research and is often useful to help indicate priorities for future research (Meyer and Sinani, 2009).

We focus on the $t$-statistic of the coefficient that represents the impact of economic diplomacy on international economic flows and the influence of study characteristics (method, research design) on this statistic. Our approach helps to uncover the effects of study characteristics on the sign and significance of the estimated effect of economic diplomacy on international flows. We start with a sample of 627 reported and (re)calculated $t$ statistics. Following Görg and Strobl (2001), Ljungwall and Tingvall (2008), Meyer and Sinani (2009) and Havranek and Irsova (2010), we estimate the following meta-regression model:

$$
\begin{aligned}
Y_{i j}= & \alpha_{0}+\beta_{1} \text { OBSERVATIONS }_{i j}+\beta_{2} \text { NOTOLS }_{i j}+\beta_{3} \text { COUNTRYSPECIFIC }_{j} \\
& +\beta_{4} \text { GRAVITYEQUATION }_{j}+\beta_{5}{\text { PRE } 2000_{j}+\beta_{6} \text { ENDOGENEITY }_{j}} \\
& +\beta_{7, \ldots, 10}\left[\text { primary dependent variable }_{i j}\right]+\beta_{11, \ldots, 18}\left[\text { instruments of diplomacy }_{i j}\right]+\varepsilon_{i j}
\end{aligned}
$$

In equation (3), we estimate how primary study characteristics influence the reported $t$-statistics of economic diplomacy on international flows. In our case, $Y_{i j}$ is the value of the $t$-statistic of the economic diplomacy coefficient derived from the $j$ th regression in the $i$ th article, $\alpha_{0}$ represents the (random) effect that controls for the commonality and dependency of estimates within and across studies, and $\varepsilon_{\mathrm{ij}}$ is the error term (Disdier and Head, 2008; Meyer and Sinani, 2009). The explanatory variables in equation (3) include empirical design and quality factors, primary dependent variables from the primary study and instruments of diplomacy used in the primary study (see Table 2 for classification and description). 
We present OLS, weighted OLS and random effects estimates of equation (3) for comparison. In the weighted OLS model, we used probability weights to correct for the structure of our sample. ${ }^{9}$ Because we have a few studies that contribute a large number of observations to our sample, each observation is weighted by the inverse of its probability of being part of our sample (Dupraz, 2013).

The random effects model is our preferred estimation. The random effects model uses more realistic assumptions about the effect size, in this case the $t$-statistic, as compared to a fixed effects model. Under fixed effects, the $t$-statistic of a given variable is assumed to be homogenous across studies; that is, the fixed effect model assumes that there is one true effect for all the studies in our sample (Hedges and Vevea, 1998). All observed differences would in that case be attributed to sampling error. Given the diversity in the investigated instruments of economic diplomacy, the differences in geographical coverage of the primary studies and the substantial variety of time periods, it is vital to allow the $t$-statistic of economic diplomacy to vary from study to study. Random effects model allows for different $t$-statistics per study which we find more realistic given the diversity of the studies under review.

Next to the influence of study characteristics on the magnitude of the $t$-statistic, we also investigate the probability of finding a significant coefficient. We can now use our more extensive sample with 963 observations. We conduct a second meta-regression analysis with the following regression model:

$$
\begin{aligned}
P\left(Y_{i j}=1\right)= & \alpha_{0}+\beta_{1} \text { OBSERVATIONS }_{i j}+\beta_{2} \text { NOTOLS }_{i j}+\beta_{3} \text { COUNTRYSPECIFIC }_{j} \\
& +\beta_{4} \text { GRAVITYEQUATION }_{j}+\beta_{5}{\text { PRE } 2000_{j}+\beta_{6} \text { ENDOGENEITY }_{j}} \\
& +\beta_{7, \ldots, 10}[\text { primary dependent variable } \\
& \text { vij } \left._{j}\right] \\
& +\beta_{11, \ldots, 18}\left[\text { instruments of diplomacy }_{i j}\right]+\varepsilon_{i j},
\end{aligned}
$$

where $y_{i j}$ is a binary variable that serves as the dependent variable. $y_{i j}$ takes the value of 1 , if the coefficient of the $i$ th regression in article $j$ is significantly positive (we use different specifications of the dependent variable that distinguish between the 5 or 1 per cent level, respectively). And, $y_{i j}=0$ if not. The relation between the dependent and the explanatory variables will be estimated with a logistic regression. Logit analysis enables calculation of the probability $p$ that a specified use or availability of economic diplomacy yields a significant $t$-stat. If this probability exceeds 0.5 , a significantly positive $t$-value is 'predicted'. We distinguish the same three sets of explanatory variables as used in equation (3). Again, we use weighted regressions and random effects to check for the robustness of our findings.

\section{b. Empirical Design}

We use the same set of explanatory variables in equations 3 and 4 . The dependent variable of course differs: in equation 3 , it is a $t$-value as reported in the primary study, and in equation 4 , it is a dummy variable that assumes the value 1 if the coefficient in the primary study is significantly positive (either as reported in the primary study or by implication) and else 0 .

\footnotetext{
${ }^{9} \mathrm{We}$ also checked our regression using analytic weights. Here $Y_{i j}$ varies at the individual level, but moderator and control variables are at the study level. Using analytic weights does not change the sign and pattern of significant explanatory variables.
} 


\section{(i) Primary Dependent Variable}

We classify the explanatory variable in the primary studies with mutually exclusive and exhaustive dummy variables for EXPORT, IMPORT, FDI and TOTALTRADE in order to indicate what explanatory variable was used in the primary study.

\section{(ii) Instruments of Economic Diplomacy}

The economic diplomacy characteristics in equation (3) include mutually exclusive and exhaustive dummies for the instrument of economic diplomacy used in the study. The economic diplomacy dummies are EMBASSIES, CONSULATES, EMBASSIESANDCONSULATES, FOREIGNEPA, TRADEMINISTERS, PMORROYAL, EPA, IPA and DIPLOMACY. These variables, respectively, capture whether the economic diplomacy coefficient pertains to embassies, consulates, embassies and consulates (combined explanatory variable), export promotion offices abroad, trade mission, state visits, EPAs and IPAs or events data scores for the diplomatic relation.

\section{(iii) Primary Study Characteristics}

The empirical design factors are COUNTRYSPECIFIC, NOTOLS, PRE2000, GRAVITYEQUATION, ENDOGENEITY and OBSERVATIONS. These variables capture the fact that a study deals with one source country only, the estimation method, the publication year, whether or not the equation in the primary study was a gravity model, whether the primary study corrected for endogeneity and the number of observations, respectively.

\section{EMPIRICAL RESULTS}

\section{a. Determinants of Magnitude t-Statistic Economic Diplomacy: Random Effects Model}

Table 4 presents the results for the OLS (with and without probability weighing) and random effects estimation of equation (3). For models 7 and 8, the sample without the 5 per cent most extreme observations is used.

The baseline uses exports as the reference for the dependent variable and embassies and consulates as the reference for the instrument of diplomacy under investigation in the primary study. Both these reference variables are the mode for their specific group of factors included in our econometric analysis. ${ }^{10}$ The references for the empirical design factors are based on studies using standard OLS regression models based on multiple country databases published after 2000. The constant term can be interpreted as the baseline meta-significance level; it is positive and highly significant in all but one model.

Models 1, 3 and 5 are based on the full sample of studies and observations. Models 2, 4 and 6 are based on a smaller sample of 29 studies and 454 observations. The difference is due to the fact that some of the primary studies do not report the number of observations used for each reported regression. Three studies, Polachek (1997), Ciuriak and Kinjo (2006), Volpe Martincus et al. (2010a), drop out entirely because the number of observations used for the regressions in their papers is not provided. Likewise, observations of Rose's (2007) extensive sensitivity analyses can no longer be included when accounting for the number of

${ }^{10}$ Export is used in 455 of 627 cases and embassies and consulates in 176 cases. 


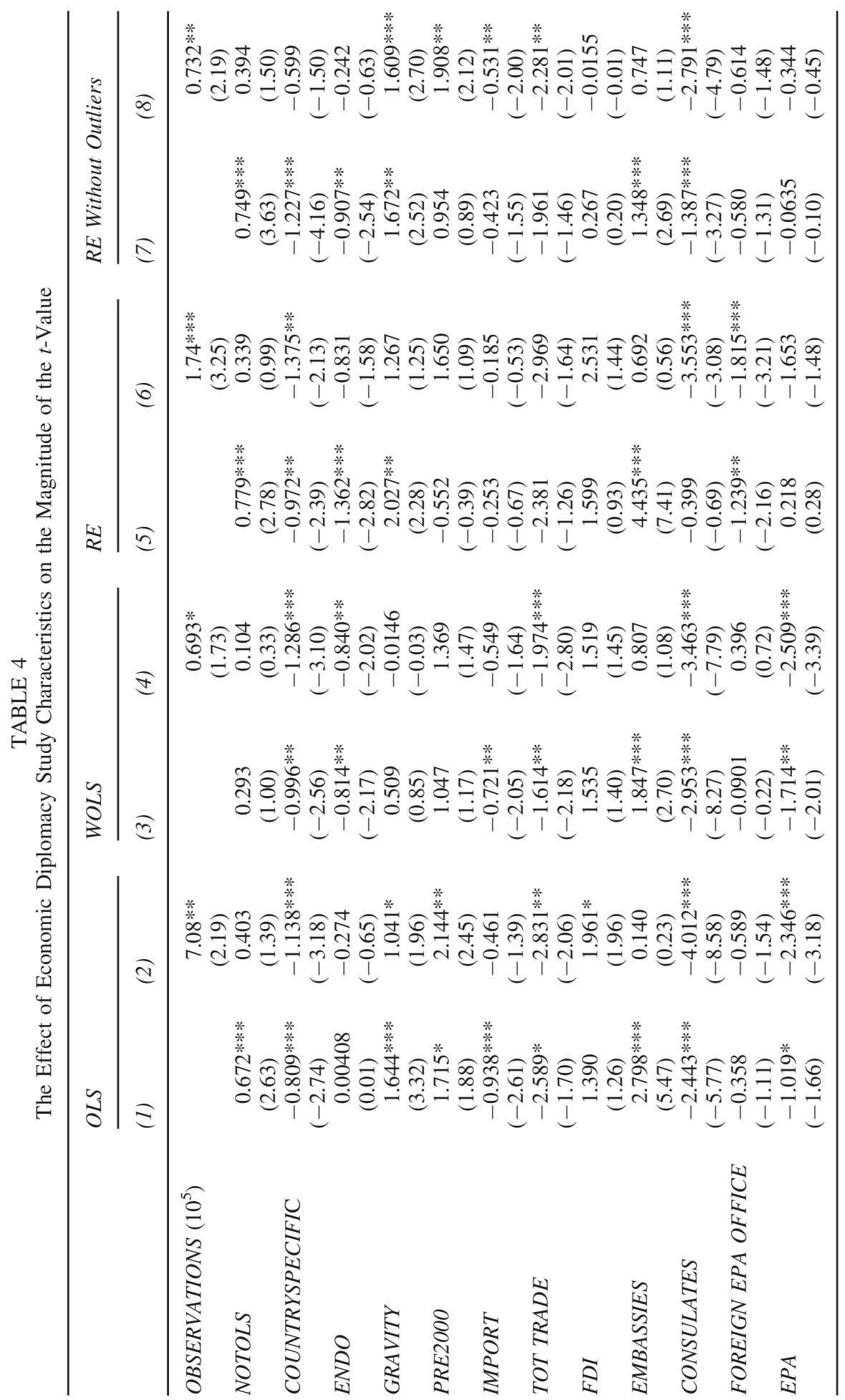




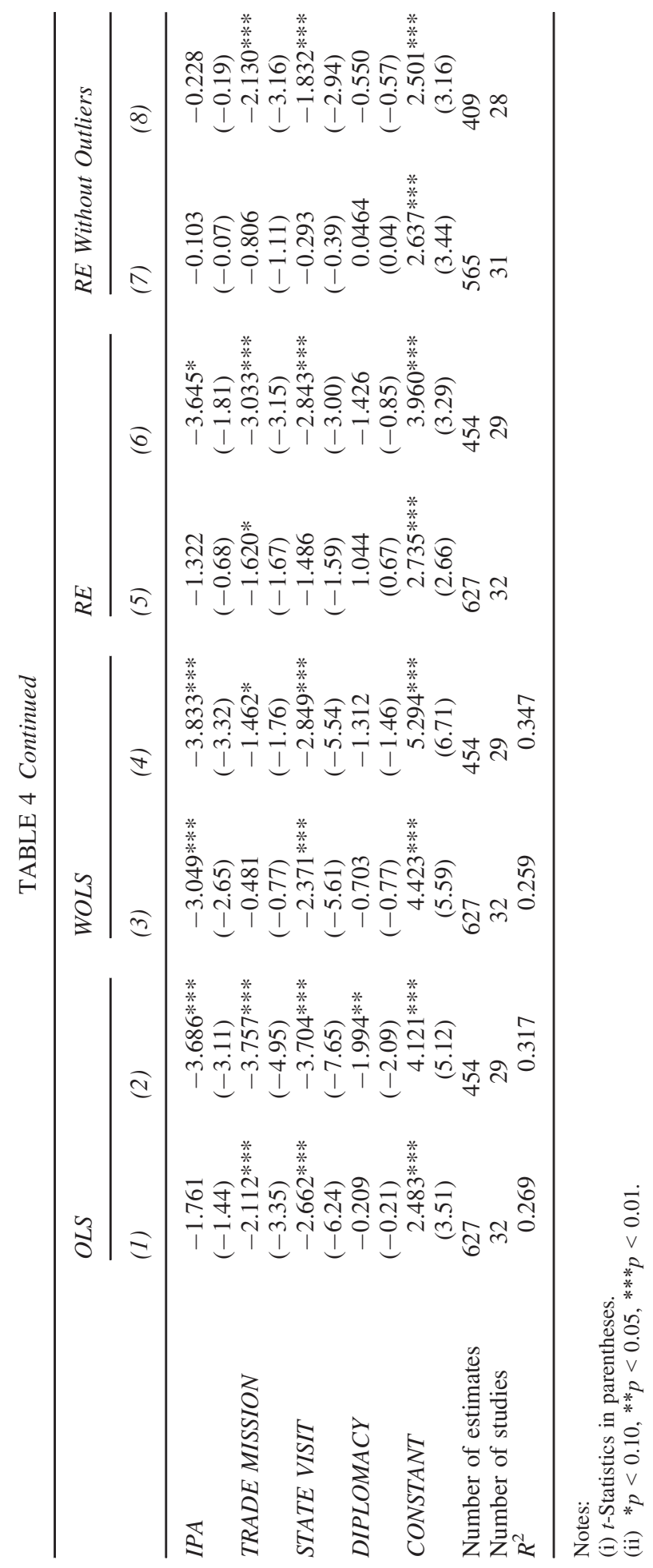


FIGURE 2

Funnel Plot with Pseudo 95 per cent Confidence Limits

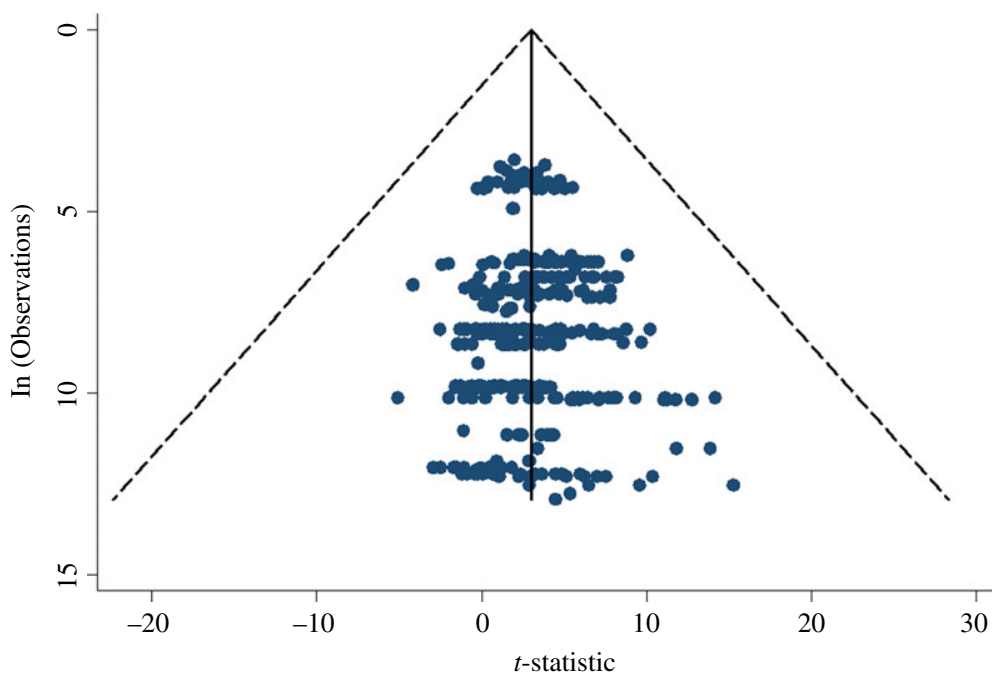

observations. ${ }^{11}$ Studies that use a larger number of observations are a priori expected to find higher $t$-statistics. This is also reflected in the direction and significance of OBSERVATIONS. This finding (in accordance with the indicative funnel plot in Figure 2) implies that no strong indications exist for publication and/or sample size bias in the primary studies.

Focusing attention on our preferred random effects models, we find that empirical design factors play an important role in the reported results of the primary studies that investigate the effect of economic diplomacy. Primary studies conducted on a single country basis $($ COUNTRYSPECIFIC $=1)$ that correct for endogeneity $($ ENDOGENEITY $=1)$ are associated with lower $t$-values. ${ }^{12}$ Gravity trade studies $(G R A V I T Y=1)$ report more significant results. Alternatives to OLS $(N O T O L S=1)$ are not structurally associated with more significant coefficients. The measure of the dependent variable is not associated with the magnitude of the $t$ statistic indicating that studies on FDI, imports, exports and total trade can be meaningfully combined in our meta-analysis.

The instrument of diplomacy that is investigated in the primary study influences the significance of the coefficient in the primary study. If the primary study uses EMBASSIES as a proxy for economic diplomacy, higher $t$-values are reported. The EMBASSIES dummy is positive, but not always significant. The insignificant results are caused by sampling effects. Models 2, 4 and 6 leave out estimates if the number of observations used in the primary studies is not reported. It is this loss of estimates that is driving the change from significant to insignificant for our EMBASSIES dummy and not the inclusion of the OBSERVATIONS variable itself. ${ }^{13}$ It may there-

\footnotetext{
${ }^{11}$ Rose (2007) provides the number of observations for his main regression results, but not for his sensitivity analyses.

12 The OLS models provide some evidence that studies published before the 2000s report higher $t$-values.

${ }^{13}$ Details are available upon request.
} 
fore be concluded that primary studies using EMBASSIES report higher $t$-statistics. If in contrast 'lower' forms of foreign representation are subject of the study, the significance of the coefficient in the primary study will be significantly lower. The results indicate that studies taking embassies and consulates as one explanatory variable may lead to a problematic generalisation about the effectiveness of the diplomatic network. Our regression analyses show that regressions using embassies will give more significant coefficients than the embassies and consulates benchmark. Consulates are systematically associated with lower levels of significance. Grouping the two (embassies versus consulates) into one (embassies and consulates) thus leads to an average significance that is too high for consulates and too low for embassies.

STATE VISITS and TRADE MISSIONS stand out negatively in all eight models. Primary studies reporting coefficients for these instruments tend to find a significantly lower $t$-statistic as compared to our established benchmark (compare Table 3). The remaining proxies for economic diplomacy, that is export and investment promotion offices, export promotion units within embassies (our FOREIGN EPA OFFICE dummy) and the diplomatic relation, are weakly related to a lower magnitude of the $t$-statistic. The sign is always negative, but many of our specifications are not significant.

\section{b. Logit Estimates of Factors Explaining Economic Diplomacy Significance}

In order to broaden our sample, we resort to an analysis that does not focus on the actual $t$-value but on the minimal significance level as reported in the primary studies. The cost of this procedure is the loss of information on the actual size of the $t$-values. The gain is that we can increase our sample by 54 per cent. Our logit meta-regressions show the relationship between, on the one hand, the empirical design, the dependent variable under investigation and the characteristics of economic diplomacy and, on the other hand, the likelihood of finding statistically significant coefficients for economic diplomacy.

Table 5 presents the logit estimates of equation (4). We investigate two variants: in the first variant, we require that the primary study reports significance at the 5 per cent level and better (models 1, 2 and 3); in the second variant, the dependent variable is assigned value 1 if the reported significance in the primary study is at the 1 per cent level and better (models 4, 5 and 6). The reference case is similar to the one deployed earlier: a primary study that measures the impact of foreign representation (embassies and consulates) on exports using OLS and based on multiple source countries. The models perform well in terms of correct predictions. Model 1 predicts reported 5 per cent significance correctly in 76 per cent of the cases. The share of correct in-sample predictions increases for models 4 and 5 ( 1 per cent significance) from 73 to 82 per cent. Table 5 reports sensitivity and specificity of the four logit models. Sensitivity, the true positive rate, measures the correctly identified proportion of actual positives. True positives are the predicted significant coefficients for economic diplomacy. Specificity measures the proportion of true negatives, that is insignificant coefficients of economic diplomacy, which are correctly identified. As expected, the models that include OBSERVATIONS generally perform better on both sensitivity and specificity.

The performance of models (1), (2), (4) and (5) in classifying economic diplomacy coefficients as significant or insignificant can also be illustrated by plotting the fraction of true positives out of the positives versus the fraction of false positives out of the negatives (the ROC curve in Figure 3). The larger the area under the ROC curve, the better the global 


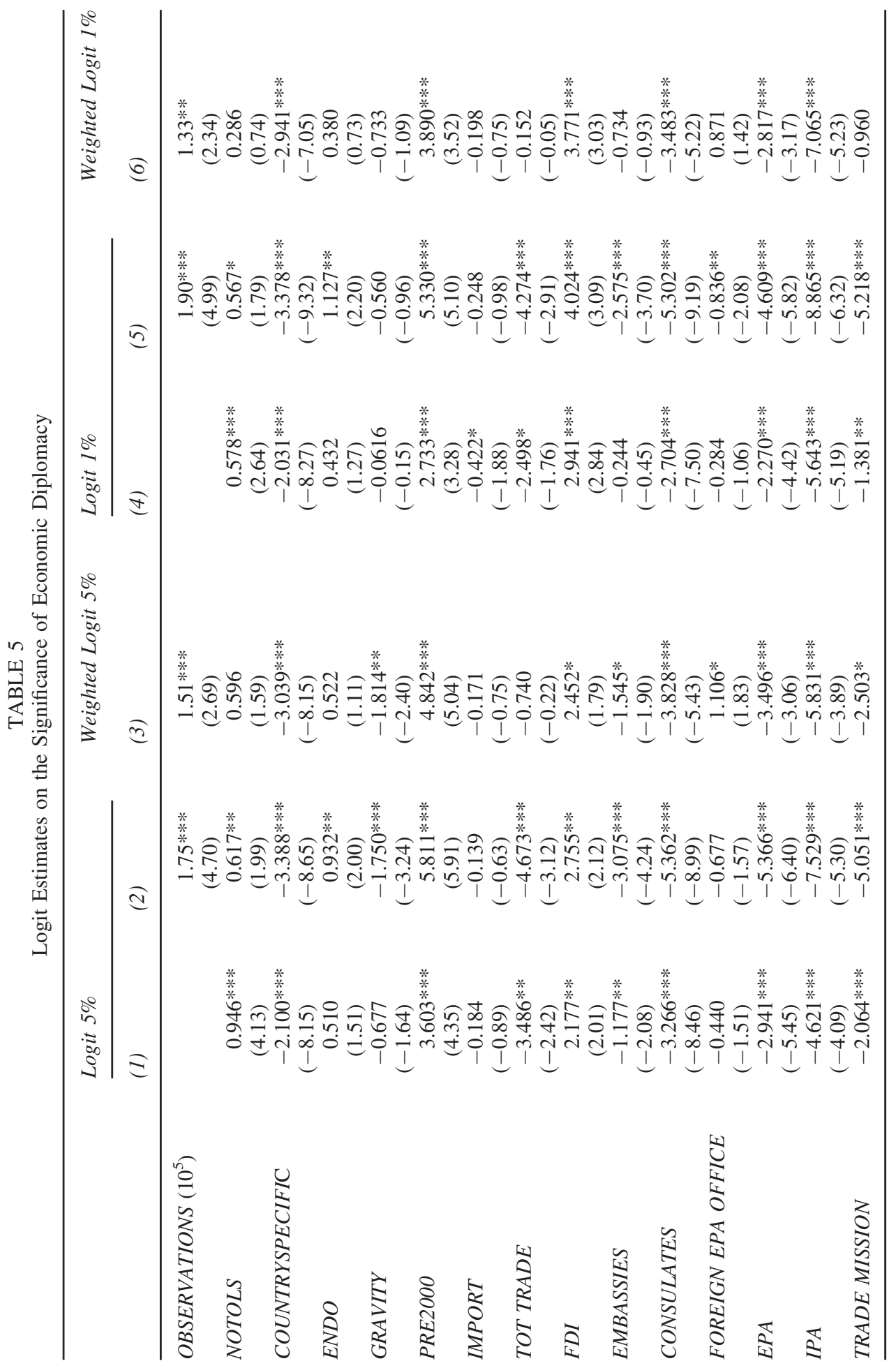




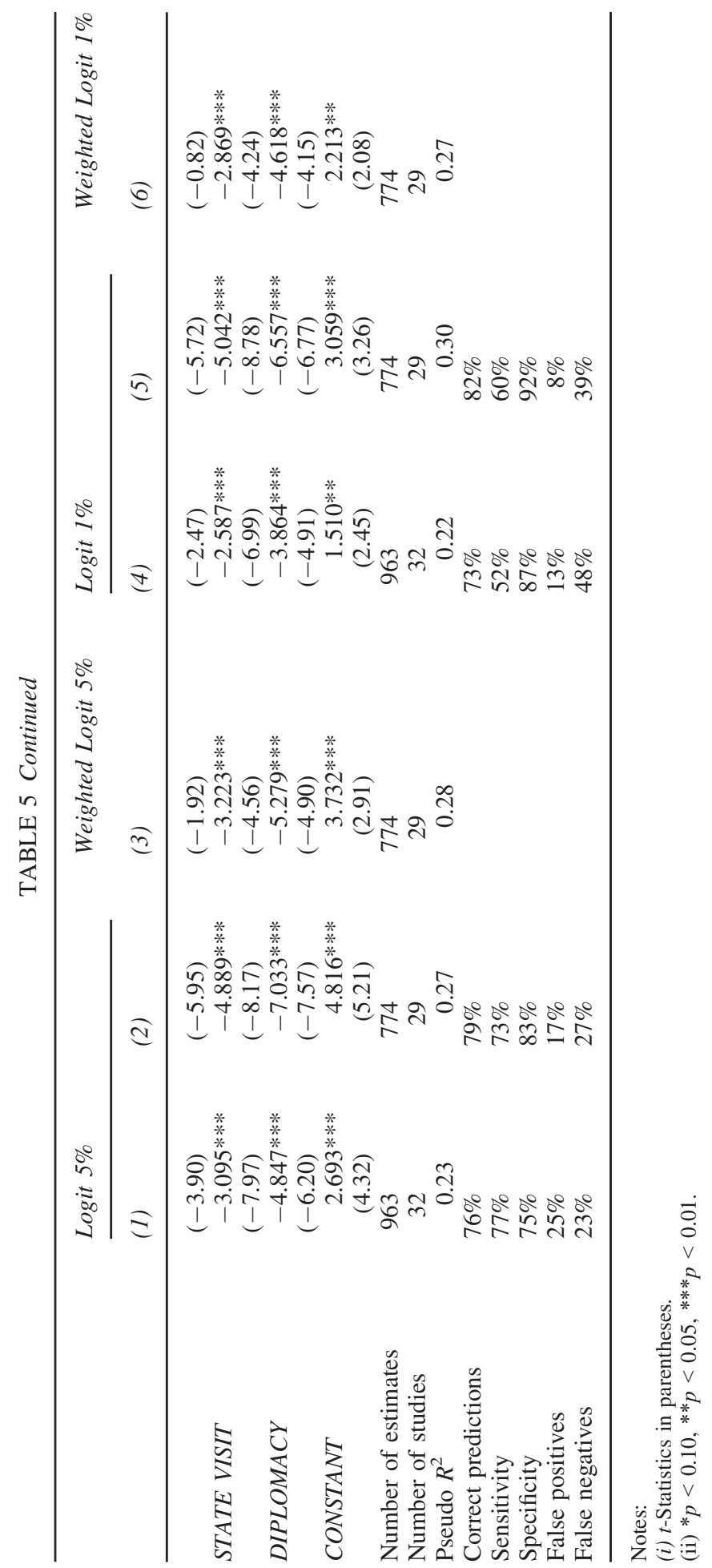


FIGURE 3

Model 1, 2, 4 and 5 ROC Curve

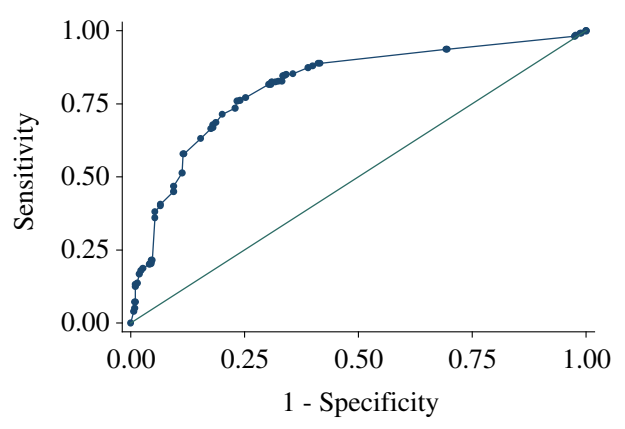

Area Under ROC Curve $=0.8141$

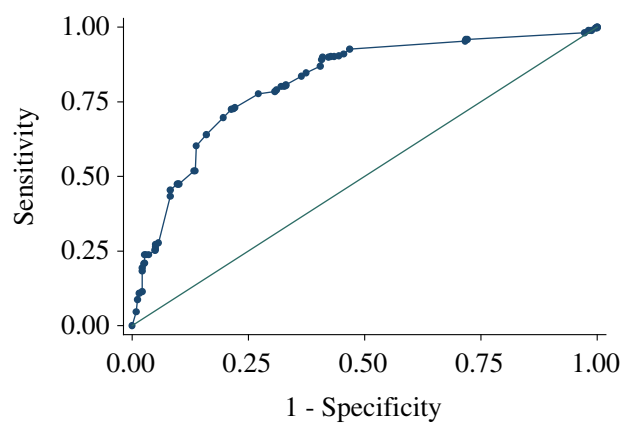

Area Under ROC Curve $=0.8151$

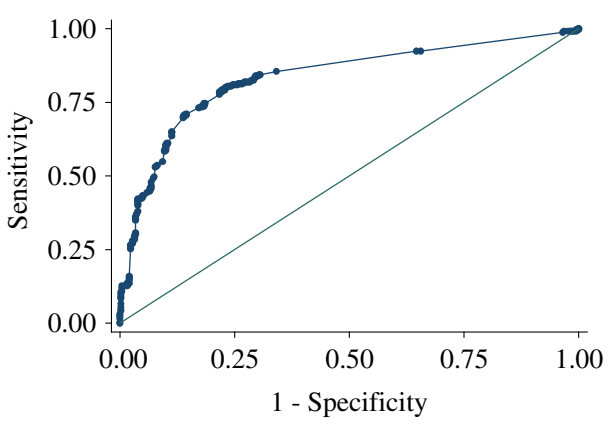

Area Under ROC Curve $=0.8340$

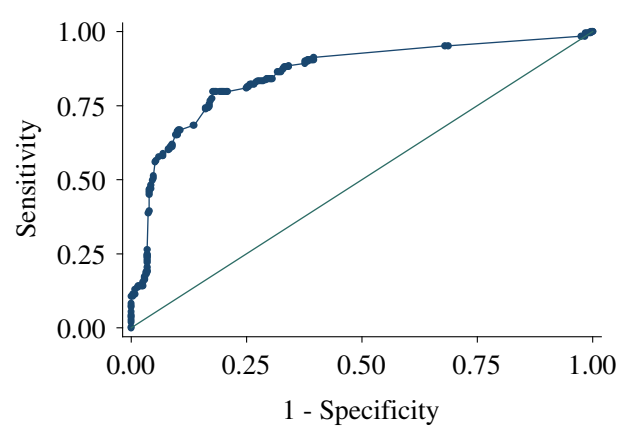

Area Under ROC Curve $=0.8562$

performance of the diagnostic test. A perfect diagnostic test would yield an area under the ROC curve of 1 , representing 100 per cent sensitivity (no false negatives) and 100 per cent specificity (no false positives). All models perform relatively well with areas between 81 and 86 per cent.

The logit analysis of significance levels in Table 5 agrees with the random effects analysis of $t$-values in Table 4 regarding OBSERVATIONS (primary studies with more observations are more likely to report significant coefficients of economic diplomacy), COUNTRYSPECIFIC (it is less likely that studies with one source country report significant coefficients), IMPORT (insignificant), TOTAL TRADE (the primary study is less likely to report significant coefficients when it investigates total trade), CONSULATES (studies that specifically study consulates as opposed to a summary measure for consulates and embassies are less likely to report significant coefficients), TRADE MISSION and STATE VISIT (all are associated with a lower probability of reporting significant coefficients). These findings are robust with respect to sample, estimation technique and significance variant.

In contrast to the results in Table 4, the logit analysis find that studies published before the year $2000(P R E 2000=1)$ are significantly more likely to report positive results at both the 5 
and 1 per cent significance levels. ${ }^{14} \mathrm{We}$ also see this for studies that correct for endogeneity problems $($ ENDOGENEITY $=1$; models 2 and 6). Primary studies with FDI as dependent variable are more likely to find significant results. For $E P A$ and $I P A$, we find highly significant negative coefficients, a result that is also supported by the OLS and WOLS estimates in Table 4. Primary studies that use EMBASSIES alone are less likely to report significant coefficients.

All in all, harvesting more binary information from primary studies is rewarding. The analyses confirm our hypothesis of the diverging effects within the economic diplomacy network. Also the negative influence of source country-specific data sets on the significance of economic diplomacy coefficients is confirmed. These are important results that should be taken into account in the design of future studies.

\section{c. Sensitivity Analysis}

Given the emerging and interdisciplinary nature of the economic diplomacy research field, we test our findings for various possible sample and definition effects. Thus far, we have used a broad definition of economic diplomacy based on Bayne and Woolcock (2003), Saner and Yiu (2003) and Lee and Hudson (2004). We will use a different definition of diplomacy that does not include the elements of the paper of Saner and Yiu (2003), that is domestic investment and export promotion institutions. What remains is a more homogeneous set of economic diplomacy variables that mainly concentrate on the actions of diplomats within the foreign network.

We also investigate the sensitivity of our meta-regression analysis for subsamples of papers published in peer-reviewed (international) economics journals, and exclude working papers and papers that do not correct for endogeneity, respectively.

We test the same baseline as presented earlier. Models (1)-(6) report random effects estimates, and the absolute $t$-value is the dependent variable. Models (7)-(12) report logit estimates and predict the likelihood of finding significant primary study results at the 5 per cent level or better.

Generally the results of the sensitivity analyses are comparable with the earlier reported meta-regression analyses. Study characteristics influence the empirical results of primary studies across all samples and estimation techniques. Studies that focus on a single source country $($ COUNTRYSPECIFIC $=1)$ are associated with lower $t$-values. Studies that use OLS do not significantly generate higher $t$-values than studies using more advanced econometric techniques. Regarding the instruments of economic diplomacy, both the random effects and logit estimates indicate lower significance levels for studies that use CONSULATES and STATE VISITS. The earlier identified differences between the random effects and logit estimates concerning our EMBASSY, DIPLOMACY and ENDOGENEITY dummy are consistent across all sensitivity analyses. Compared to the random effect regressions, we again see that the logit analysis is more likely to predict positive and significant deviations from the baseline model for studies published before $2000(P R E 2000=1)$ and a lower likelihood of finding significance for EPAs.

Across the tested samples in Table 6, FDI is no longer associated with higher $t$-values, but this mainly reflects the small number of studies of varying quality, something not uncommon

\footnotetext{
14 The former is in line with the results for OLS and WOLS in Table 4; the latter finding probably is a spurious finding as GRAVITY has become negative (it was positive and significant), while corrections for endogeneity by and large occur in the gravity models.
} 


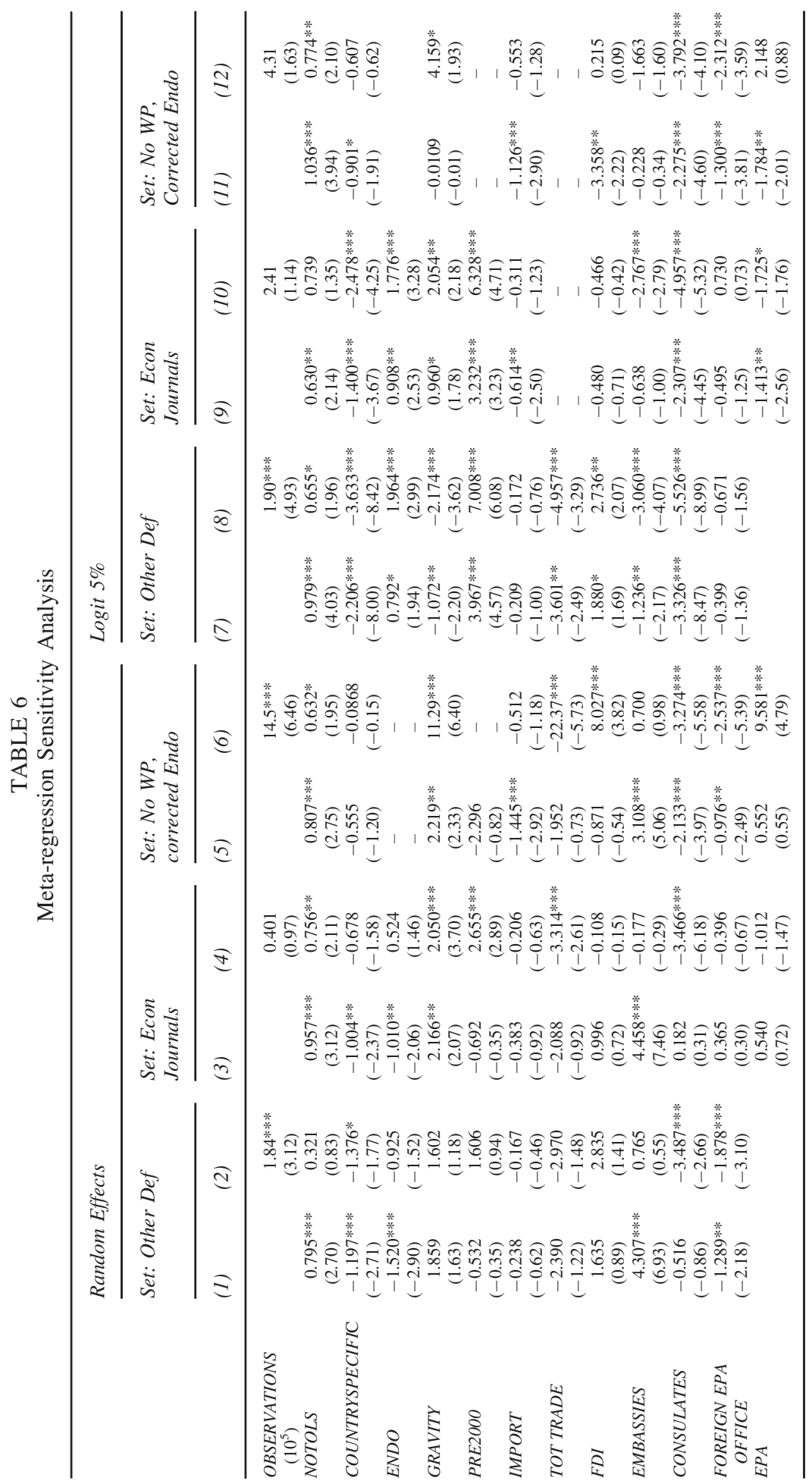




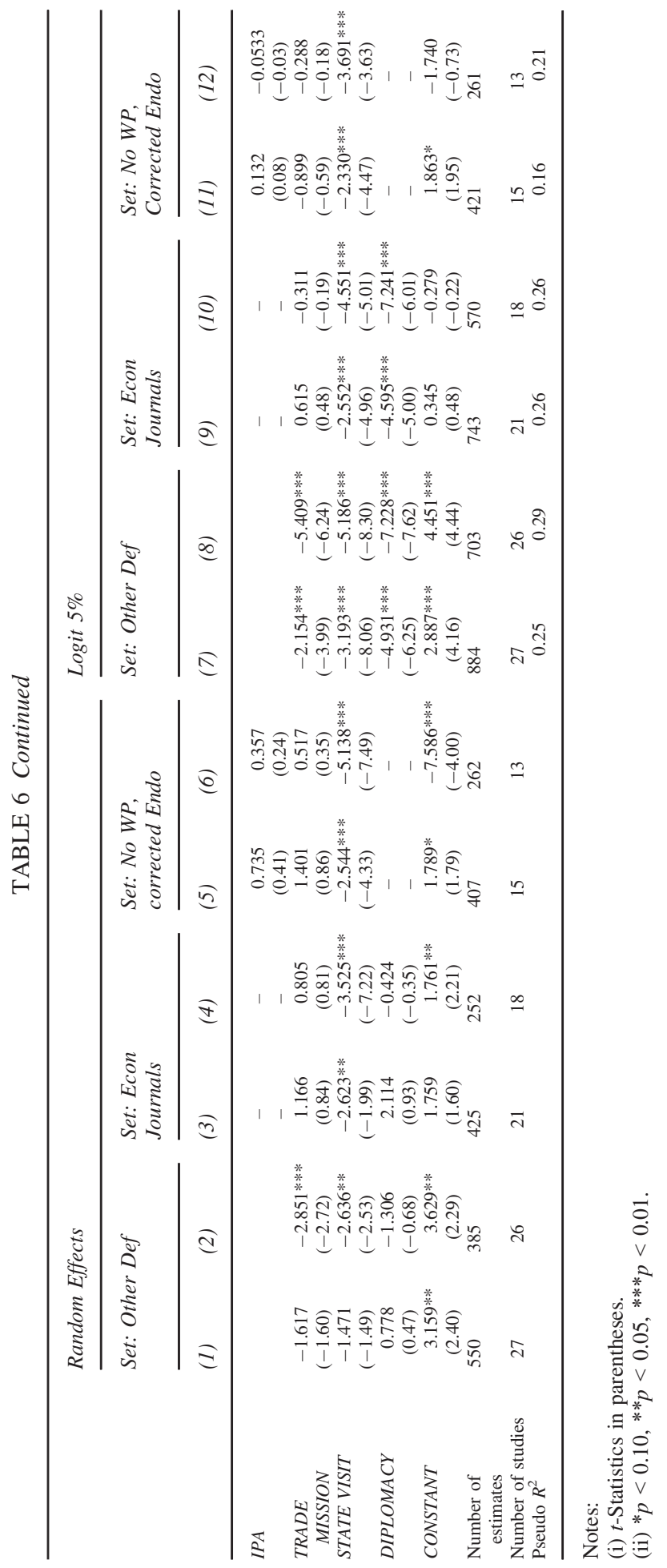


in an emerging research field. Here, our conclusion is simply that the effect of economic diplomacy on FDI should be subject to further investigation to reduce the variance between study results.

As to the differences that are analytically relevant, we note the lower and less significant $t$-values for the base line using the subsample of primary papers published in peer-reviewed economics journals. In this multidisciplinary field, the implication is that the economic profession is less convinced of the significance of economic diplomacy. This is also reflected in the results for the subsample without working papers (economics tends to focus on published peer-reviewed articles) and papers that do not address causality (correction for causality is a common requirement in economics). The earlier reported higher meta-significance is thus partly driven by working paper publications and publications in other research fields than economics (predominantly international relations). From this same analysis on subsamples, we learn that the economics papers are more likely to produce positive and significant $t$-statistics when a gravity model $(G R A V I T Y=1)$ is used.

This sensitivity analysis shows that it is rewarding to take into account several subsamples in a meta-analysis, especially when the research topic is interdisciplinary. ${ }^{15}$ Although it is common practise in meta-analysis to analyse all available papers that address the same research question if metrics are comparable (or can be made comparable as a group), it in this case proves to be rewarding to also investigate subsamples of primary studies because best practices differ between the different scientific disciplines.

\section{CONCLUDING REMARKS}

This paper investigated whether economic diplomacy has a significant effect on trade and investment flows and what the sign of that relationship is. Due to the heterogeneity of specifications and the occurrence of substandard reporting in the primary studies, we resort to the analysis of $t$-statistics. Analysing $627 t$-statistics of 32 primary studies in the aggregate, we conclude that the bivariate evidence supports a positive and significant effect of economic diplomacy with the exception of state visits (Table 3). Our meta-regression analysis (Table 4) points towards more heterogeneity in the significance of economic diplomacy coefficients and highlights the importance of research design and other characteristics of the primary studies. In particular, we find that primary studies that study only one source country are less likely to report significant positive effects and that studies that use a variable that lumps embassies and consulates(-general) into one indicator miss that these instruments differ significantly and should thus be included as separate instruments in future research.

We also perform a logit analysis of reported discrete significance levels (not, 5 and 1 per cent) increasing our sample to 963 observations (Table 5) that by and large supports the findings on the smaller sample demonstrating robustness with respect to sample, methodology and significance variant. The logit analysis differs in two respects: studies published before 2000 are more likely to report significant coefficients and significant results, and studies that use FDI are more likely to report positive and significant impact of economic diplomacy (research on the influence of economic diplomacy of FDI is scarce: only 54 of 963 regressions deal with the effect of economic diplomacy on FDI flows, providing a clear indication that future research should deal with this issue). This approach loses information on the magnitude of the

${ }^{15}$ We thank the referees of this journal for insisting on doing the analysis for the different subsamples. 
$t$-value, but it enlarges our sample and thus also gains information. Our econometric analyses show that reported effects of economic diplomacy on trade and investment in individual studies are sensitive to model specification and that this is true in the large and the small sample and independent of the estimation technique. This analysis also reveals that there is a difference in the reported significance of economic diplomacy coefficients between research fields and published versus working papers, even after correcting for study characteristics.

The fact that we see statistically significant and economically meaningful positive coefficients for economic diplomacy does not mean that the instrument is efficient. This would demand more in depth knowledge of its benefits and costs. Also from this perspective, there is a clear need for improving the availability of data, for increasing the country coverage of the data and for better and more comprehensive reporting of findings and basic statistics.

\section{REFERENCES}

(Primary studies in the meta-analysis data-set are marked by *)

Afman, E. R. and M. Maurel (2010), 'Diplomatic Relations and Trade Reorientation in Transition Countries', in P. A. G. van Bergeijk and S. Brakman (eds.), The Gravity Model in International Trade: Advances and Applications (Cambridge: Cambridge University Press), 278-95.*

Alvarez, R. E. (2004), 'Sources of Export Success in Small- and Medium-Sized Enterprises: The Impact of Public Programs', International Business Review, 13, 3, 383-400.

Bayne, N. and S. Woolcock (2003), The New Economic Diplomacy: Decision Making and Negation in International Economic Relations (Aldershot: Ashgate).

Bernard, A. and J. B. Jensen (2004), 'Why Some Firms Export', Review of Economics and Statistics, 86, 2, 561-9.

Biglaiser, G. and K. DeRouen Jr (2007), 'Following the Flag: Troop Deployment and US Foreign Direct Investment', International Studies Quarterly, 51, 4, 835-54.*

Bobonis, G. J. and H. J. Shatz (2007), 'Agglomeration, Adjustment, and State Policies in the Location of Foreign Direct Investment in the United States', The Review of Economics and Statistics, 89, 1, 30-43.*

Bradburn, J. M., J. J. Deeks and D. G. Altman (1998), 'Metan - A Command for Meta-analysis in Stata', The Stata Technical Bulletin, STB, 44, 1, 4-15.

Ciuriak, D. and S. Kinjo (2006), 'The Role of Embassies and Consulates in Promoting Trade: Does Economic Freedom in the Host Economy Matter?', in J. M. Curtis and D. Ciuriak (eds.), Trade Policy Research 2005. Available at: http://ssrn.com/abstract=1549324 (accessed 10 January 2014).*

Creusen, H. and A. Lejour (2011), 'Uncertainty and the Export Decisions of Dutch Firms', discussion paper 183 (The Hague: CPB)**

Creusen, H. and A. Lejour (2013), 'Market Entry and Economic Diplomacy', Applied Economics Letters, 20, 5, 504-7.

Disdier, A.-C. and K. Head (2008), 'The Puzzling Persistence of the Distance Effect on Bilateral Trade', The Review of Economics and Statistics, 90, 1, 37-48.

Djankov, S. and P. Murrell (2002), 'Enterprise Restructuring in Transition: A Quantitative Survey', Journal of Economic Literature, 40, 3, 739-92.

Dupraz, Y. (2013), 'Using Weights in Stata', Available at: http://www.parisschoolofeconomics.eu/docs/ dupraz-yannick/using-weights-in-stata(1).pdf (accessed at 14 January 2014).

Ferguson, S. and R. Forslid (2011), 'The Heterogeneous Effects of Trade Facilitation: Theory and Evidence', European Trade Study Group Conference Paper (Copenhagen: 2011 ETSG conference).*

Francis, J. and C. Collins-Dodd (2004), 'Impact of Export Promotion Programs on Firm Competencies, Strategies and Performance: The Case of Canadian High-technology SMEs', International Marketing Review, 21, 4/5, 474-95.

Gencturk, E. and M. Kotabe (2001), 'The Effect of Export Assistance Program Usage on Export Performance: A Contingency Explanation', Journal of International Marketing, 9, 2, 51-72. 
Gil, S., R. Llorca and J. A. Martinez-Serrano (2008), 'Measuring the Impact of Regional Export Promotion: The Spanish Case', Papers in Regional Science, 87, 1, 139-47.*

Gil-Pareja, S., R. Llorca-Vivero and J. A. Martinez-Serrano (2007), 'The Impact of Embassies and Consulates on Tourism', Tourism Management, 28, 3, 355-60.*

Gil-Pareja, S., R. Llorca-Vivero, J. A. Martinez-Serrano and F. R. Silvente (2011), Regional Export Promotion Offices and Trade Margins, 1993-2008 (Valencia, Spain: Spanish Regions, University of Valencia). Available at: https://editorialexpress.com/cgi-bin/conference/download.cgi?db_name= MWITFall2011\&paper_id=65 (accessed 11 October 2012).*

Görg, H. and E. Strobl (2001), 'Multinational Companies and Productivity Spill-overs: A Meta-analysis with a Test for Publication Bias', Economic Journal, 111, 475, 723-39.

Greenwald, B. and J. E. Stiglitz (1986), 'Externalities in Economies with Imperfect Information and Incomplete Markets', Quarterly Journal of Economics, 101, 2, 229-64.

Hajakawa, K., H.-H. Lee and D. Park (2010), 'Do Export Promotion Agencies Increase Exports?', IDE Discussion Paper 313 (Wakaba: Institute of Developing Economies).*

Harding, T. and B. S. Javorcik (2007), 'Developing Economies and International Investors: Do Investment Promotion Agencies Bring them Together?', Policy Research Working Papers 4339 (Washington, DC: World Bank). Available at: https://openknowledge.worldbank.org/handle/10986/7289 License: CC BY 3.0 Unported (accessed 24 January 2014).*

Harris, R. and Q. C. Li (2005), Review of Literature: The Role of International Trade and Investment in Business Growth and Development (London: DTI).

Hausmann, R. and D. Rodrik (2003), 'Economic Development as Self Discovery', Journal of Development Economics, 72, 2, 603-33.

Havranek, T. and Z. Irsova (2010), 'Meta-analysis of Intra-industry FDI Spillovers: Updated Evidence', Czech Journal of Economics and Finance, 60, 2, 151-74.

Head, K. and J. Ries (2006), 'Do Trade Missions Increase Trade?', Sauder School of Business Working Paper Series (Vancouver: University of Britisch Columbia).*

Hedges, L. V. and J. L. Vevea (1998), 'Fixed-and Random-effects Models in Meta-Analysis', Psychological Methods, 3, 4, 486-504.

Hogan, P. (1991), 'Some Institutional Aspects of Export Promotion in Developing Countries', in P. Hogan, D. Keesing and A. Singer (eds.), The Role of Support Services in Expanding Manufactured Exports in Developing Countries (Washington, DC: EDI, World Bank), 39-56.

Kang, K. (2011), 'Overseas Network of Export Promotion Agency and Export Performance: The Korean Case', Contemporary Economic Policy, 29, 2, 274-83.*

Keesing, D. B. and A. Singer (1991), 'Assisting Manufactured Exports Through Services: New Methods and Improve Policies', in P. Hogan, D. Keesing and A. Singer (eds.), The Role of Support Services in Expanding Manufactured Exports in Developing Countries (Washington, DC: Economic Development Institute, World Bank), 19-38.

Keshk, O. M. G., B. M. Pollins and R. Reuveny (2004), 'Trade Still Follows the Flag: The Primacy of Politics in a Simultaneous Model of Interdependence and Armed Conflict', Journal of Politics, 66, 4, 1155-79.

Kowalski, P., M. Buge, M. Sztajerowska and M. Egeland (2013), 'State-owned Enterprises: Trade Effects and Policy Implications', OECD Trade Policy Papers, No. 147, (Paris: OECD Publishing).

Lazzaroni, S. and P. A. G. van Bergeijk (2015), 'Macroeconomics of Natural Disasters: Strengths and Weaknesses of Meta-analysis and Review of Literature', Risk Analysis, 35, 6, 1050-72.

Lederman, D., M. Olarreaga and L. Lucy Payton (2006), 'Export Promotion Agencies: What Works and What Doesn't?', World Bank Policy Research Working Paper 4044 (Washington, DC: World Bank).*

Lederman, D., M. Olarreaga and L. Lucy Payton (2010), 'Export Promotion Agencies: Do They Work?', Journal of Development Economics, 91, 2, 257-65.*

Lee, D. and D. Hudson (2004), 'The Old and New Significance of Political Economy in Diplomacy', Review of International Studies, 30, 3, 343-60.

Ljungwall, C. and P. G. Tingvall (2008), 'Is China Different? A Meta Analysis of the Effect of Foreign Direct Investment on Domestic Firms', Working Paper 2 (Stockholm: Stockholm School of economics).

Mebratie, A. D. and P. A. van Bergeijk (2011), 'Firm Heterogeneity and Development: A Meta-analysis of FDI Productivity Spill-overs', Journal of International Trade \& Economic Development, 22, 1, 52-70. 
Mebratie, A. D. and P. A. van Bergeijk (2013), 'Firm Heterogeneity and Development: A Meta-analysis of FDI Productivity Spillovers', The Journal of International Trade \& Economic Development, 22, 1, 53-74.

Meyer, K. E. and E. Sinani (2009), 'When and Where Does Foreign Direct Investment Generate Positive Spill Overs? A Meta-analysis', Journal of International Business Studies, 40, 7, 1075-94.

Moons, S. (2012), 'What are the Effects of Economic Diplomacy on the Margins of Trade?', International Journal of Diplomacy and Economy, 1, 2, 147-62.

Morriset, J. (2003), 'Does a Country Need a Promotion Agency to Attract Foreign Direct Investment? A Small Analytical Model Applied to 58 Countries', Research Working Paper 3028 (Washington, DC: World Bank).*

Newbold, P. (1995), Statistics for Business and Economics, 4th edn (Englewood Cliffs, NJ: PrenticeHall).

Nigh, D. (1985), 'The Effect of Political Events on Unites States Direct Foreign Investment: A Pooled Time-series Cross-sectional Analysis', Journal of International Business Studies, 16, 1, 1-17.*

Nitsch, V. (2007), 'State Visits and International Trade', World Economy, 30, 4, 1797-816.*

Okano Heijmans, M. (2011), 'Conceptualizing Economic Diplomacy: Crossroads of International Relations, Economics, IPE, and Diplomatic Studies', The Hague Journal of Diplomacy, 6, 1-2, 7-36.

Polachek, S. (1997), 'Why Democracies Cooperate More and Fight Less: The Relationship Between International Trade and Cooperation', Review of International Economics, 5, 3, 295-309.*

Polachek, S., C. Seiglie and J. Xiang (2007), 'The Impact of Foreign Direct Investment on International Conflict', Defence and Peace Economics, 18, 5, 415-29.*

Pollins, B. M. (1989a), 'Does Trade Still Follow the Flag?', American Political Science Review, 83, 2, 465-80.

Pollins, B. M. (1989b), 'Conflict, Cooperation and Commerce', American Journal of Political Science, 33, 3, 737-61.*

Rangan, S. and R. Z. Lawrence (1999), 'Search and Deliberation in International Exchange: Learning from Multinational Trade About Lags, Distance Effects, and Home Bias', Working Paper 7012 (Cambridge, MA: National Bureau of Economic Research).

Rauch, J. E. (1996), 'Trade and Search: Social Capital, Sogo Shosha and Spill Overs', Working Paper 5618 (Cambridge, MA: National Bureau of Economic Research).

Reuveny, R. and H. Kang (1998), 'Bilateral Trade and Political Conflict/Cooperation: Do Goods Matter?', Journal of Peace Research, 35, 5, 581-602.

Rose, A. K. (2007), 'The Foreign Service and Foreign Trade: Embassies as Export Promotion', The World Economy, 30, 1, 22-238.*

Rose, A. K. and T. D. Stanley (2005), 'A Meta-analysis of the Effect of Common Currencies on International Trade', Journal of Economic Surveys, 19, 3, 347-65.

Saner, R. and L. Yiu (2003), 'International Economic Diplomacy: Mutations in Post-modern Times', Discussion Papers in Diplomacy, 84, 1-41 (The Hague: Clingendael).

Segura-Cayuela, R. and J. M. Vilarrubia (2008), 'The Effects of Foreign Service on Trade Volumes and Trade Partners' Working Paper 0808 (Madrid: Banco de Españna).*

Seringhaus, F. and G. Botschen (1991), 'Cross-national Comparison of Export Promotion Services: The Views of Canadian and Austrian Companies', Journal of International Business Studies, 22, 1, $115-33$.

Seringhaus, F. H. R. and P. J. Rosson (1998), 'Management and Performance of International Trade Fair Exhibitors: Government Stands vs. Independent Stands', International Marketing Review, 15, 5, 398-412.

Shamsuddoha, A. K. and M. Yunus Ali (2006), 'Mediated Effects of Export Promotion Programs on Firm Export Performance', Asia Pacific Journal of Marketing and Logistics, 18, 2, 93-110.

Stanley, T. D. (2001), 'Wheat From Chaff: Meta-analysis as Quantitative Literature Review', Journal of Economic Perspectives, 15, 3, 131-50.

Stanley, T. D. and H. Docouliagos (2012), Meta-regression Analysis in Economics and Business (New York: Routledge).

Summary, R. M. (1989), 'A Political-economic Model of US Bilateral Trade', Review of Economics and Statistics, 71, 1, 179-82.*

van Bergeijk, P. A. and S. Brakman (eds.) (2010), The Gravity Model in International Trade: Advances and Applications (Cambridge: Cambridge University Press). 
van Bergeijk, P. A. G. (1992), 'Diplomatic Barriers to Trade', De Economist, 140, 1, 45-64.*

van Bergeijk, P. A. G. (1994), Economic Diplomacy, Trade and Commercial Policy (Cheltenham: Edward Elgar).*

van Bergeijk, P. A. G. (2009), Economic Diplomacy and the Geography of International Trade (Cheltenham: Edward Elgar).

van Bergeijk, P. A. G., H. de Groot and M. Yakop (2011a), 'The Economic Effectiveness of Diplomatic Representation: An Economic Analysis of its Contribution to Bilateral Trade', The Hague Journal of Diplomacy, 6, 1-2, 101-20.*

van Bergeijk, P. A. G., J. Melissen and M. Okono-Heijmans (2011b), Economic Diplomacy: Economic and Political Perspectives (Leiden: Martinus Nijhoff Publishers).

van Biesebroeck, J., E. Yu and S. Chen (2011), 'The Impact of Trade Promotion Services on Canadian Exporter Performance', Discussion Paper 8597 (London: CEPR).

van Veenstra, M. L., van Yakop M. and van Bergeijk P. A. G. (2011), 'The Geography of Trade and the Network Effects of Economic Diplomacy in the South', in M. Murshed, P. Goulart and L. A. Serino (eds.), South-South Globalization: Challenges and Opportunities for Development (Abington: Routledge), 172-94.*

Volpe Martincus, C. (2010), Odyssey in International Markets: An Assessment of the Effectiveness of Export Promotion in Latin America and the Caribbean. Special Report on Integration and Trade (Washington, DC: Inter-American Development Bank).

Volpe Martincus, C. and J. Carballo (2011), 'Export Promotion Activities in Developing Countries: What Kind of Trade Do They Promote?', The Journal of International Trade \& Economic Development, 21, 4, 1-40.

Volpe Martincus, C., A. Estevadeordal, A. Gallo and J. Luna (2010a), 'Information Barriers, Export Promotion Institutions, and the Extensive Margin of Trade', Review of World Economics, 146, 1, 91-111.*

Volpe Martincus, C. A., J. Carballo and P. Garcia (2010b), 'Firms Size and the Impact of Export Promotion Programms', in D. Ciuriak (ed.), Trade Policy Research 2010 (Ottowa: Department of Foreign Affairs and International Trade), 191-244.

Wooster, R. B. and D. S. Diebel (2010), 'Productivity Spillovers from Foreign Direct Investment in Developing Countries: A Meta-regression Analysis', Review of Development Economics, 14, 3, 640-55.

Yakop, M. and P. A. G. van Bergeijk (2011), 'Economic Diplomacy, Trade and Developing Countries', Cambridge Journal of Regions, Economy and Society, 4, 2, 253-67.* 